\title{
First report of fatty acids in Mimosa diplotricha bee pollen with in vitro lipase inhibitory activity
}

\author{
Phanthiwa Khongkarat $^{1}$, Prapun Traiyasut ${ }^{2}$, Preecha Phuwapraisirisan ${ }^{3}$, Chanpen Chanchao ${ }^{\text {Corresp. } 4}$ \\ 1 Program in Biotechnology, Faculty of Science, Chulalongkorn University, Bangkok, Thailand \\ 2 Program in Biology, Faculty of Science, Ubon Ratchathani Rajabhat University, Ubon Ratchathani, Thailand \\ 3 Department of Chemistry, Faculty of Science, Chulalongkorn University, Bangkok, Thailand \\ 4 Department of Biology, Faculty of Science, Chulalongkorn University, Bangkok, Thailand \\ Corresponding Author: Chanpen Chanchao \\ Email address: chanpen.c@chula.ac.th
}

Bee pollen (BP) is full of nutrients and phytochemicals, and so it is widely used as a health food and alternative medicine. Its composition and bioactivity mainly depend on the floral pollens. In this work, BP collected by Apis mellifera with different monoculture flowering crops (BP1-6) were used. The types of floral pollen in each BP were initially identified by morphology, and subsequently confirmed using molecular phylogenetic analysis. Data from both approaches were consistent and revealed each BP to be monofloral and derived from the flowers of Camellia sinensis L., Helianthus annuus L., Mimosa diplotricha, Nelumbo nucifera, Xyris complanata, and Ageratum conyzoides for BP1 to BP6, respectively. The crude extracts of all six BPs were prepared by sequential partition with methanol, dichloromethane (DCM), and hexane. The crude extracts were then tested for the in vitro (i) $\alpha$-amylase inhibitory, (ii) acetylcholinesterase inhibitory (AChEI), and (iii) porcine pancreatic lipase inhibitory (PPLI) activities in terms of the percentage enzyme inhibition and half maximum inhibitory concentration $\left(\mathrm{IC}_{50}\right)$. The DCM partitioned extract of $X$. complanata BP (DCMXBP) had the highest active $\alpha$-amylase inhibitory activity with an $I_{50}$ value of $1,792.48 \pm 50.56 \mu \mathrm{g} / \mathrm{mL}$. The DCM partitioned extracts of $C$. sinensis $\mathrm{L}$. BP (DCMCBP) and M. diplotricha BP (DCMMBP) had the highest PPLI activities with an $\mathrm{IC}_{50}$ value of $458.5 \pm 13.4$ and $500.8 \pm 24.8 \mu \mathrm{g} / \mathrm{mL}$, respectively), while no crude extract showed any marked AChEl activity. Here, the in vitro PPLI activity was focused on. Unlike C. sinensis L. BP, there has been no previous report of $M$. diplotricha BP having PPLI activity. Hence, DCMMBP was further fractionated by silica gel 60 column chromatography, pooling fractions with the same thin layer chromatography profile. The pooled fraction of DCMMBP2-1 was found to be the most active $\left(\mathrm{IC}_{50}\right.$ of $\left.52.6 \pm 3.5 \mu \mathrm{g} / \mathrm{mL}\right)$, while nuclear magnetic resonance analysis revealed the presence of unsaturated free fatty acids. Gas chromatography with flame-ionization detection analysis revealed the major fatty acids Peerj reviewing PDF | (2021:09:65771:2:0:NEW 5 Dec 2021) 
included one saturated acid (palmitic acid) and two polyunsaturated acids (linoleic and linolenic acids). In contrast, the pooled fraction of DCMMBP2-2 was inactive but pure, and was identified as naringenin, which has previously been reported to be present in $M$. pigra L. Thus, it can be concluded that naringenin was compound marker for Mimosa BP. The fatty acids in BP are nutritional and pose potent PPLI activity. 
1 First report of fatty acids in Mimosa diplotricha bee

\section{Corresponding Author:}

Chanpen Chanchao 4

Department of Biology, Faculty of Science, Chulalongkorn University, 254 Phayathai Road, Bangkok 10330, Thailand.

E-mail address: chanpen.c@chula.ac.th

\section{Abstract}

Bee pollen (BP) is full of nutrients and phytochemicals, and so it is widely used as a health food and alternative medicine. Its composition and bioactivity mainly depend on the floral pollens. In this work, different BPs collected by Apis mellifera from different monoculture flowering crops (BP1-6) were used. The types of floral pollen in each BP were initially identified by morphology, and subsequently confirmed using molecular phylogenetic analysis. Data from both approaches were consistent and revealed each BP to be monofloral and derived from the flowers of Camellia sinensis L., Helianthus annuus L., Mimosa diplotricha, Nelumbo nucifera, Xyris complanata, and Ageratum conyzoides for BP1 to BP6, respectively. The crude extracts of all six BPs were prepared by sequential partition with methanol, dichloromethane (DCM), and hexane. The crude extracts were then tested for the in vitro (i) $\alpha$-amylase inhibitory, (ii) acetylcholinesterase inhibitory (AChEI), and (iii) porcine pancreatic lipase inhibitory (PPLI) activities in terms of the percentage enzyme inhibition and half maximum inhibitory concentration $\left(\mathrm{IC}_{50}\right)$. The DCM partitioned extract of $X$. complanata BP (DCMXBP) had the highest active $\alpha$-amylase inhibitory activity with an $\mathrm{IC}_{50}$ value of $1,792.48 \pm 50.56 \mu \mathrm{g} / \mathrm{mL}$. The DCM partitioned extracts of $C$. sinensis L. BP (DCMCBP) and M. diplotricha BP (DCMMBP) had the highest PPLI activities with an $\mathrm{IC}_{50}$ value of $458.5 \pm 13.4$ and $500.8 \pm 24.8 \mu \mathrm{g} / \mathrm{mL}$, respectively), while no crude extract showed any marked AChEl activity. Here, the in vitro PPLI activity was focused on. Unlike $C$. sinensis L. BP, there has been no previous report of $M$. diplotricha BP having PPLI activity. Hence, DCMMBP was further fractionated by silica gel 60 column chromatography, pooling fractions with the same thin layer chromatography profile. The 
pooled fraction of DCMMBP2-1 was found to be the most active $\left(\mathrm{IC}_{50}\right.$ of $52.6 \pm 3.5$ $\mu \mathrm{g} / \mathrm{mL}$ ), while nuclear magnetic resonance analysis revealed the presence of unsaturated free fatty acids. Gas chromatography with flame-ionization detection analysis revealed the major fatty acids included one saturated acid (palmitic acid) and two polyunsaturated acids (linoleic and linolenic acids). In contrast, the pooled fraction of DCMMBP2-2 was inactive but pure, and was identified as naringenin, which has previously been reported to be present in $M$. pigra L. Thus, it can be concluded that naringenin was compound marker for Mimosa BP. The fatty acids in BP are nutritional and pose potent PPLI activity.

Keywords: bee pollen, anti-lipase activity, fatty acids, phytochemicals, floral pollen

\section{Introduction}

Bee pollen (BP) is one of the economic bee products. It is derived from the flower's male gametophyte produced within anther sacs in the flowers of angiosperms, and is collected by foragers of bees and mixed with the plant's nectar, wax, and bee's saliva to compact the powder into pollen grains. The BP is then loaded into a pollen basket (corbicula), which is part of the tibia on the hind legs (Costa et al., 2019), and later stored in the hive as an essential food for the larva and adults in addition to honey, bee bread, and royal jelly. Nutritionally, BP is known as a functional food for humans and due to its high content of protein and carbohydrates, along with crude fiber, amino acids, vitamins, minerals, and fatty acids (Yang et al., 2013). However, floral identification of BP should be done prior to the consumption as a few people display allergic and anaphylactic reactions after consumption of certain floral pollens (Shahali, 2015; Jagdis and Sussman, 2012). In particular, bee pollen composed of ash (Oleaceae), oak (Fagaceae), willow and poplar (Salicaceae), or corn (Zea mays) as the dominant floral pollen requires caution (Vieths et al., 2012).

In addition, BP is also composed of secondary metabolites (polyphenols and flavonoids) of plants (Rzepecka-Stojko et al., 2015). In folk medicine, BP has long been used as a tonic and a multipurpose remedy, and it is widely known that various phytochemicals in BP are bioactive. Chilean BP has been reported to have an antioxidative activity in both the 2,2'-azino-bis(3-ethylbenzothiazoline-6-sulfonate (ABTS) radical and 2,2-diphenyl-1-picryl-hydrazyl-hydrate (DPPH) scavenging capacity assays. Both activities were related to their polyphenols content, especially caffeic acid, coumaric acid, luteolin, and pinocembrin (Munoz et al., 2020).

In addition, BP harvested by the stingless bee, Scaptotrigona affinis postica, in Brazil showed an anti-inflammatory activity by inhibiting cyclooxygenase (COX-1 and COX-2) and reducing the edema in male Mus musculus mice (Swiss strain) when using the carrageenan- and dextran-induced paw edema tests (Lopes et al., 2020).

However, the composition and phytochemicals in BP mainly depend on the bee species, and its botanical and geographical origins. For example, alkaloids in the BP of Catharanthus roseus, saponins in the BP of Momordica charantia, sterols and flavinoids in Butea monosperma, and tannins in Syzygium cuminii all showed a potent antidiabetic activity (Ghoshal and Saoji, 2013). In addition, in Slovakia, Apis mellifera BP dominant in rape Brassica napus floral pollen had a higher antioxidative activity than BP dominant 
90 in poppy Papaver somniferum L. and sunflower Helianthus annuus L. floral pollen, 91 respectively, (Fatrcova-Sramkova et al., 2013).

The BP collected by the stingless bee, Melipona fasciculata, was harvested from three cities in Brazil and revealed different anti-inflammatory and antinociceptive activities, with the highest activities in the BP from Chapadinha City, while the BP collected by $M$. fasciculata showed higher anti-inflammatory and antinociceptive activities than that collected by $A$. mellifera (Lopes et al., 2019).

The BPs collected from different geographical regions in Brazil had different chemical compositions and bioactivities (Araújo et al., 2017). Monofloral BPs of Eucalyptus spp. and multifloral BP exhibited potent inhibitory activities against $\alpha-$ amylase, acetylcholinesterase (AChE), tyrosinase, lipoxygenase, lipase, and hyaluronidase, but with different half maximal inhibitory concentration $\left(\mathrm{IC}_{50}\right)$ values. Monofloral BP of Cocos nucifera and Miconia spp. also exhibited antioxidant properties.

From 18 samples of mono- and poly-floral BPs harvested from 16 different localities in South Korea, all were found to have anti-oxidant, anti-human $\beta$-amyloid precursor cleavage enzyme, AChE inhibitory (AChEl), anti-human intestinal bacteria, and anticancer activities, but with different $I C_{50}$ values (Zou et al., 2020).

In terms of their nutrient compositions, polyfloral BPs gave more benefits than monofloral ones, in terms of having more diverse secondary metabolite-like compounds. Metabolomics analysis revealed that beehive pollen from diverse species of plants contained key ingredients for health (lactate, a pentose sugar, myo-inositol, phosphate, and a furanose), but not in BP dominated by canola floral pollen (Arathi et al., 2018). In addition, $A$. mellifera fed with polyfloral BP were more tolerant to the microsporidian Nosema ceranae (Di Pasquale et al., 2013). However, in terms of the quality control standards for BP consumption by humans and its industrial production, monofloral BP is more fruitful because known bioactive molecules and their precise concentration can be more easily and economically ascertained (Kostic et al., 2021).

The BPs from several countries, including Argentina, Brazil, China, and Spain, have been commercialized after their chemical compositions and bioactivities were reported (Sindhi et al., 2013). However, little is known about the BP in Thailand, which is high in both bee and plant diversities (Chantarudee et al., 2012; Rattanawannee and Chanchao, 2011).

In order to identify the bioactive molecules in BP that originated from native plants in Thailand, monofloral BP harvested by $A$. mellifera from six types of floral pollen was examined. The type of floral pollen in each of the BPs (BP1 to BP6) were first identified by palynological analysis using light microscopy (LM) and scanning electron microscopy (SEM), and then by molecular analysis examining the partial sequence of the second internal transcribed sequence (ITS-2) of the ribosomal RNA genes. Then, each of the six BPs was sequentially extracted with methanol, dichloromethane (DCM), and hexane, and the partitioned extracts were screened for $\alpha$-amylase, AChE, and lipase inhibitory activities. Among these bioactivities, the lipase inhibitory activity was targeted due to there being a few previous reports on this activity in BP. The most active sample was subjected to further fractionation by chromatography, and the obtained fractions were analyzed for purity/composition by thin layer chromatography (TLC) and, for fatty 
134

135

136

137

138

139

140

141

142

143

144

145

146

147

148

149

150

151

152

153

154

155

156

157

158

159

160

161

162

163

164

165

166

167

168

169

170

171

172

173

174

175

176

acids, by gas chromatography with a flame ionization detector (GC-FID) after conversion to fatty acid methyl esters (FAMEs). Seemingly pure active compounds were analysed by nuclear magnetic resonance (NMR). A chemical compound marker was revealed in the typical bee pollen. The obtained data support the safety and benefit of BP consumption.

\section{Materials \& Methods Chemicals and reagents}

The chemicals ( $\alpha$-amylase, acarbose, AChE from electric eel, acetylthiocholine iodide, 5,5'-dithiobis (2-nitrobenzoic acid), physostigmine, crude porcine pancreatic lipase type II, p-nitrophenyl palmitate, and orlistate) used in this study were from SigmaAldrich, Darmstadt, Germany.

\section{Sample collection}

Six A. mellifera BPs (BP1 to BP6), one from each of six localities in Thailand, were collected in 2018, that were suspected, based on the available flowers near the hives, of being monofloral and derived from Camellia sinensis L. and Mimosa diplotricha in Chiangmai province (BP 1 and BP3, respectively), Helianthus annuus L. in Lopburi province (BP2), Nelumbo nucifera in Nakhon Sawan province (BP4), Xyris complanata in Udon Thani province (BP5), and Ageratum conyzoides in Lamphun province (BP6), repectively. The BP samples used were dried using a specific process and stored at room temperature $\left(25^{\circ} \mathrm{C}\right)$ until used.

\section{Identification of the bee pollen}

\section{By palynological analysis}

The morphology of each BP was initially observed under LM at 400X magnification. Briefly, the respective BP was dispersed in distilled water $\left(\mathrm{d}-\mathrm{H}_{2} \mathrm{O}\right)$ on a glass slide, and pictures and characteristics of the BPs were recorded and compared to the reported publications.

Next, the morphology was observed under SEM at 1,500-5,000X magnification. Briefly, BPs were washed three times with ethanol (5 min each), and then three times with acetone (5 min each). The samples were then sent for SEM and energy dispersive X-ray spectrometry (6610LV; Tokyo, Japan) imaging at the Scientific and Technological Research Equipment Center of Chulalongkorn University. The morphology and characteristics of the BPs were recorded and compared to the reported publications.

By molecular analysis

Each BP was further identified by comparison of the partial ITS-2 DNA sequences (Richardson et al., 2015) to the species-annotated sequences in the GenBank database. For this, the genomic DNA was extracted from approximately $100 \mathrm{mg}$ of BP using a DNeasy Plant Mini Kit (catalog no. 69104, Qiagen, Germany). The quality of the extracted DNA was determined by $1.2 \%(\mathrm{w} / \mathrm{v})$ agarose gel electrophoresis and the ratio of absorbance at 260 and $280 \mathrm{~nm}$. After DNA isolation, the ITS-2 region was amplified using the polymerase chain reaction (PCR) with the forward (5'-ATGCGATACTTG 
177 GTGTGAAT-3') and reverse (5'-GACGCTTCTCCAGACTACAAT-3') primers. Each PCR 178 amplification was performed in a $25 \mu \mathrm{L}$ final reaction volume comprised of $12.5 \mu \mathrm{L}$ of $2 \mathrm{X}$ 179 EmeraldAmp® PCR master mix (catalog \# RR300A, Takara), $1 \mu \mathrm{L}$ of each of primer (10 $180 \mu \mathrm{M}$ ), at least $30 \mathrm{ng}$ of genomic DNA template, and nuclease-free $\mathrm{d}-\mathrm{H}_{2} \mathrm{O}$. The PCR 181 thermal cycling was performed as $98{ }^{\circ} \mathrm{C}$ for $30 \mathrm{~s}$, followed by 30 cycles of $98{ }^{\circ} \mathrm{C}$ for 10 $182 \mathrm{~s}, 59{ }^{\circ} \mathrm{C}$ for $30 \mathrm{~s}$, and $72{ }^{\circ} \mathrm{C}$ for $30 \mathrm{~s}$; and then a final $72{ }^{\circ} \mathrm{C}$ for $10 \mathrm{~min}$. The PCR product (500 bp) was checked by $1.2 \%(\mathrm{w} / \mathrm{v})$ agarose gel electrophoresis in $1 \mathrm{X}$ Tris-borateEDTA buffer at $80 \mathrm{~V}$ for $45 \mathrm{~min}$ after Ecodye staining. The PCR product was extracted using QIAquick PCR Purification Kit (catalog no. 28106, Qiagen, Germany) and sent for commercial direct sequencing. The obtained sequences were used to search for homologous sequences in the GenBank database of the National Center for Biotechnology Information using the Basic Local Alignment Search Tool for nucleotide (BLASTn) algorithm.

\section{Crude extraction and partition}

The extraction and partition was modified from Chantarudee et al. (2012). Each BP $(140 \mathrm{~g})$ was mixed with $800 \mathrm{~mL}$ of methanol $(\mathrm{MeOH})$, shaken at $100 \mathrm{rpm}, 15^{\circ} \mathrm{C}$ for 18 $\mathrm{h}$, and then centrifuged at $6,000 \mathrm{rpm}, 4^{\circ} \mathrm{C}$, for $15 \mathrm{~min}$. The supernatant was collected, while the solid residue (pellet) was re-extracted three more times in the same manner with $800 \mathrm{~mL}$ of $\mathrm{MeOH}$ each time. The supernatants were pooled and evaporated under reduced pressure at a maximum temperature of $40-45^{\circ} \mathrm{C}$ to obtain the crude $\mathrm{MeOH}$ extracts, which were kept at $-20^{\circ} \mathrm{C}$ in the dark until used.

The $\mathrm{MeOH}$ crude extracts were sequentially partitioned by hexane (low polarity), to eliminate the lipid and non-polar compounds; DCM (medium polarity), and finally $\mathrm{MeOH}$ (high polarity). To this end, the six $\mathrm{MeOH}$ crude extracts (one for each of BP1-6) were separately dissolved in $\mathrm{MeOH}$ until it was not sticky and then mixed with an equal volume of hexane in a separating funnel and left to phase separate, whereupon the upper hexane phase was collected. The lower $\mathrm{MeOH}$ phase was then further extracted with hexane in the same manner twice more, and the hexane extracts were pooled and evaporated under reduced pressure at a maximum temperature of $40-45^{\circ} \mathrm{C}$ to yield the hexane partitioned (HX) extracts of BP1-6 (bee pollen from $C$. sinensis $L$., $H$. annuus L., M. diplotricha, N. nucifera, $X$. complanata, and $A$. conyzoides, respectively, and designated as HXCBP, HXHBP, HXMBP, HXNBP, HXXBP, and HXABP, respectively). Meanwhile, the residual $\mathrm{MeOH}$ phase was then extracted with an equal volume of DCM three times in the same manner as above (except the DCM phase was the lower layer), with the pooled DCM extracts evaporated as above. The sample from this step was named the DCM partitioned extracts of $C$. sinensis L., $H$. annuus L., M. diplotricha, $N$. nucifera, $X$. complanata and $A$. conyzoides flower BP (BP1-6, respectively), and designated as DCMCBP, DCMHBP, DCMMBP, DCMNBP, DCMXBP, and DCMABP, respectively.

Finally, the residual $\mathrm{MeOH}$ phase was evaporated as above to yield the $\mathrm{MeOH}-$ partitioned (MT) extract of $C$. sinensis L., $H$. annuus L., M. diplotricha, N. nucifera, $X$. 
219 complanata and $A$. conyzoides flower BPs (BP1-6, respectively, and designated as 220 MTCBP, MTHBP, MTMBP, MTNBP, MTXBP, and MTABP, respectively). All partitioned

221

222

223

224

225

226

227

228

229

230

231

232

233

234

235

236

237

238

239

240

241

242

243

244

245

246

247

248

249

250

251

252

253

254

255

256

257

258 extracts were kept at $-20{ }^{\circ} \mathrm{C}$ in the dark until used to test the biological activities.

\section{In vitro $\alpha$-amylase inhibitory activity}

The $\alpha$-amylase inhibition assay was modified from Akoro et al. (2017). The partitioned extract of BP was dissolved in dimethyl sulfoxide (DMSO) and subsequently diluted in $\mathrm{MeOH}$ at different concentrations (125, 250, 500, 1,000, and 2,000 $\mu \mathrm{g} / \mathrm{mL}$ ). Two hundred and fifty $\mu \mathrm{L}$ of $\alpha$-amylase solution [0.5 units $(\mathrm{U}) / \mathrm{mL}]$ dissolved in buffer $\left[\mathrm{Na}_{2} \mathrm{HPO}_{4} / \mathrm{NaH}_{2} \mathrm{PO}_{4}(0.02 \mathrm{M})\right.$ and $\left.\mathrm{NaCl}(0.006 \mathrm{M})\right]$ at $\mathrm{pH} 6.9$ was mixed with $250 \mu \mathrm{L}$ of the extract and incubated at $37^{\circ} \mathrm{C}$ for $10 \mathrm{~min}$. After that, $250 \mu \mathrm{L}$ of the starch solution $\left[0.5 \%(\mathrm{w} / \mathrm{v})\right.$ in $\left.\mathrm{d}-\mathrm{H}_{2} \mathrm{O}\right]$ was added and incubated at $37^{\circ} \mathrm{C}$ for $10 \mathrm{~min}$. The reaction was terminated by the addition of $500 \mu \mathrm{L}$ DNSA reagent $(12 \mathrm{~g}$ of sodium potassium tartrate tetrahydrate in $8.0 \mathrm{~mL}$ of $2 \mathrm{M} \mathrm{NaOH}$, and $20 \mathrm{~mL}$ of $96 \mathrm{mM}$ of 3,5-dinitrosalicylic acid solution) and was heated at $85-90{ }^{\circ} \mathrm{C}$ for $5 \mathrm{~min}$ in a water bath. The mixture was cooled to room temperature and was diluted with $5 \mathrm{~mL}$ of $\mathrm{d}-\mathrm{H}_{2} \mathrm{O}$, and the absorbance was measured at $540 \mathrm{~nm}\left(\mathrm{~A}_{540}\right)$ using a UV-Visible spectrophotometer (Sunrise, Tecan, Austria). Acarbose was used as the positive inhibitor. Each sample was performed and measured in triplicate. The inhibitory percentage of $\alpha$-amylase was calculated using the equation given below.

Percentage of $\alpha$-amylase inhibition $=[\{(A-B)-(C-D)\} /(A-B)] \times 100$ where $A$ is the $A_{540}$ after incubation without an extract, $B$ is the $A_{540}$ after incubation without an extract and $\alpha$-amylase, $C$ is the $A_{540}$ after incubation with an extract and $\alpha-$ amylase, and $D$ is the $A_{540}$ after incubation with an extract, but without $\alpha$-amylase.

The \% a-amylase inhibition ( $\mathrm{Y}$ axis) was plotted against the extract concentrations $\left(\mathrm{X}\right.$ axis) and the $\mathrm{IC}_{50}$ value was obtained using regression analysis.

\section{In vitro AChEl inhibitory activity}

Evaluation of the AChEl activity was modified from Li et al. (2019) based on Ellman's method. Firstly, $160 \mu \mathrm{L}$ of TTB [50 mM Tris-HCl buffer $\mathrm{pH} 8$ with $1 \%(\mathrm{v} / \mathrm{v})$ Trition X-100], $20 \mu \mathrm{L}$ of the extract dissolved in DMSO $(500 \mu \mathrm{g} / \mathrm{mL})$, and $10 \mu \mathrm{L}$ of $0.2 \mathrm{U} / \mathrm{mL}$ AChE from electric eel dissolved in $0.1 \%(\mathrm{w} / \mathrm{v})$ bovine serum albumen in TTB were mixed and incubated at $4{ }^{\circ} \mathrm{C}$ for $20 \mathrm{~min}$. Then, $5 \mu \mathrm{L}$ of $15 \mathrm{mM}$ acetylthiocholine iodide in $\mathrm{d}-\mathrm{H}_{2} \mathrm{O}$ and

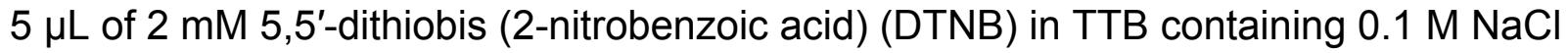
and $0.02 \mathrm{M} \mathrm{MgCl}_{2}$ were added per well and incubated at $37^{\circ} \mathrm{C}$ for $20 \mathrm{~min}$. The absorbance at a wavelength of $412 \mathrm{~nm}\left(\mathrm{~A}_{412}\right)$ was measured using a microplate reader (Sunrise, Tecan, Austria). Physostigmine was used as the positive control. All the reactions were performed in triplicate. The percentage inhibition was calculated as follows.

Percentage of $\mathrm{AChE}$ inhibition $=[\{(\mathrm{A}-\mathrm{B})-(\mathrm{C}-\mathrm{D})\} /(\mathrm{A}-\mathrm{B})] \times 100$ 
259

260

261

262

263

264

265

266

267

268

269

270

271

272

273

274

275

276

277

278

279

280

281

282

283

284

285

286

287

288

289

290

291

292

293

294

295

296

297

298

where $A$ is the $A_{412}$ after incubation without an extract, $B$ is the $A_{412}$ after incubation without an extract and $A C h E, C$ is the $A_{412}$ after incubation with an extract and $A C h E$, and $D$ is the $A_{412}$ after incubation with an extract, but without $A C h E$.

The $\%$ AChEI ( $Y$ axis) was plotted against the extract concentrations and the $\mathrm{IC}_{50}$ values were obtained using linear or non-linear regression analysis.

\section{In vitro porcine pancreatic lipase inhibitory (PPLI) activity}

The enzyme solution was prepared immediately before use as previously described (Jamous et al., 2018) with some modifications. Crude PPL type II was suspended in 50 $\mathrm{mM}$ Tris- $\mathrm{HCl}$ buffer $\mathrm{pH} 8$ to a concentration of $2 \mathrm{mg} / \mathrm{mL}$. The suspension was mixed and centrifuged at 16,000x g for $10 \mathrm{~min}$. The clear supernatant was recovered and kept. The PPLI assay was adapted from Maqsood et al. (2017). Briefly, $100 \mu \mathrm{L}$ of the extract at different concentrations $(200,400,600,800$, and $1,000 \mu \mathrm{g} / \mathrm{mL}$ for DCMCBP, DCMMBP, DCMNBP, DCMXBP, and DCMABP; and 12.5, 25, 50, 100, and $200 \mu \mathrm{g} / \mathrm{mL}$ for DCMMBP2 and DCMMBP2-1) dissolved in DMSO and $600 \mu \mathrm{L}$ of $50 \mathrm{mM}$ Tris- $\mathrm{HCl}$ buffer ( $\mathrm{pH}$ 8.0) were pre-incubated with $200 \mu \mathrm{L}$ of $2 \mathrm{mg} / \mathrm{mL}$ of PPL solution at $37^{\circ} \mathrm{C}$ for $30 \mathrm{~min}$. Afterwards, $100 \mu \mathrm{L}$ of $1.5 \mathrm{mM}$ of $p$-nitrophenyl palmitate (p-NPP) in isopropanol was added and incubated at $37^{\circ} \mathrm{C}$ for $2 \mathrm{~h}$. Lipase activity was determined by measuring the hydrolysis of $p$-NPP to $p$-nitrophenol product via measuring the absorbance at 410 $\mathrm{nm}\left(\mathrm{A}_{410}\right)$ using a microplate reader. Orlistat was used as the positive standard. Each sample was performed and measured in triplicate. The percentage of lipase inhibition was calculated according the following formula.

Percentage of lipase inhibition $=[\{(A-B)-(C-D)\} /(A-B)] \times 100$ where $A$ is the $A_{410}$ after incubation without an extract, $B$ is the $A_{410}$ after incubation without an extract and lipase, $C$ is the $A_{410}$ after incubation with an extract and lipase, and $D$ is the $A_{410}$ after incubation with an extract, but without lipase.

The \% lipase inhibition ( $Y$ axis) was plotted against the extract concentrations ( $X$ axis) and the $\mathrm{IC}_{50}$ values were obtained from the graph.

\section{Enrichment of active fractions}

Among the mentioned bioactivities, the extract with the most potent in vitro PPLI activity was used for further fractionation (enrichment) by silica gel 60 column chromatography (SiG60-CC).

\section{(A) Large scale SiG60-CC (500-mL column)}

A 500-mL column was packed with fine SiG60 (Merck). The partitioned extract (6.0 g) was dissolved in $20 \mathrm{~mL}$ of $\mathrm{MeOH}$ and combined with $20 \mathrm{~g}$ of rough SiG60 and allowed to dry, whereupon it was poured over the surface of the packed SiG60 column. The column was first eluted with $6.5 \mathrm{~L}$ of DCM, followed by $8.5 \mathrm{~L}$ of $7 \%(\mathrm{v} / \mathrm{v}) \mathrm{MeOH}$ in $\mathrm{DCM}$ and then $3.5 \mathrm{~L}$ of $\mathrm{MeOH}$, respectively. Eluted fractions $(250 \mathrm{~mL}$ each) were collected, and the solvent was removed by evaporation under reduced pressure at a 
299

300

301

302

303

304

305

306

307

308

309

310

311

312

313

314

315

316

317

318

319

320

321

322

323

324

325

326

327

328

329

330

331

332

333

334

335

336

337

338

maximum temperature of $40-45^{\circ} \mathrm{C}$. The pattern of chemical compounds in each fraction was profiled by TLC (see below). Fractions with the same TLC pattern were pooled together and tested for in vitro PPLI activity using the assay as above.

(B) Small scale SiG60-CC (250-mL column)

A $250-\mathrm{mL}$ column was packed with fine SiG60. The active fraction $(300 \mathrm{mg})$ was dissolved in $5 \mathrm{~mL}$ of $\mathrm{MeOH}$ and combined with $5 \mathrm{~g}$ of rough SiG60 and allowed to dry, whereupon it was poured over the surface of the packed SiG60 column. The column was eluted with $1,000 \mathrm{~mL}$ of $2 \%(\mathrm{v} / \mathrm{v}) \mathrm{MeOH}$ in $\mathrm{DCM}$ and then $500 \mathrm{~mL}$ of $\mathrm{MeOH}$, respectively. Eluted fractions ( $7 \mathrm{~mL}$ each) were collected, and the solvent was removed by evaporation under reduced pressure at a maximum temperature of $40-45^{\circ} \mathrm{C}$. The pattern of chemical compounds in each fraction was profiled by TLC (see below). Fractions with the same TLC pattern were assumed to be chemically similar and were pooled. After that, each fraction was tested for its in vitro PPLI activity using the assay as above.

One-dimensional TLC

A $5 \times 5 \mathrm{~cm}^{2}$ TLC plate with silica as the immobile phase was prepared. The sample was spotted onto the solvent front line of the plate by a capillary tube, allowed to dry at room temperature, and then resolved in one direction using the appropriate mobile phase solvent of $7 \%(\mathrm{v} / \mathrm{v}) \mathrm{MeOH}$ : DCM. The resolved compounds on the TLC plate were visualized under UV light at $254 \mathrm{~nm}$ or by dipping in 3\% (v/v) anisaldehyde in $\mathrm{MeOH}$ and heating over a hot plate.

\section{Chemical structure analysis by NMR}

Among the fractions obtained from the SiG60-CC (250-mL size), the most active fraction for PPLI activity was evaporated and analysed. Briefly, the evaporated sample was dissolved in an appropriate deuterated solvent (Chloroform-d or MeOH-d4, Merck) at a ratio of $5-20 \mathrm{mg}$ of compound to $600 \mu \mathrm{L}$ of deuterated solvent. It was then transferred to an NMR tube and shaken until completely dissolved. The NMR spectrum was recorded on a Jeol JNM-ECZ (JNM-ECZ500R, Tokyo, Japan) $500 \mathrm{MHz}$ operated at $500 \mathrm{MHz}$ for ${ }^{1} \mathrm{H}-\mathrm{NMR}$ nuclei in order to detect the functional groups using tetramethylsilane as the internal standard. The chemical shift in $\delta(\mathrm{ppm})$ was assigned with reference to the signal from the residual protons in the deuterated solvents, while the chemical shift and $\mathrm{J}$ coupling value were determined using the MestReNova version 12.0.3 software.

\section{Preparation of FAMEs}

A portion $(26.7 \mathrm{mg})$ of the fraction with the highest PPLI activity obtained from SiG60-CC (250-mL size), was added to absolute $\mathrm{MeOH}(2 \mathrm{~mL})$, followed by $0.5 \mathrm{~mL}$ of concentrated $\mathrm{H}_{2} \mathrm{SO}_{4}$. The reaction mixture was stirred and heated at $60^{\circ} \mathrm{C}$ for $3.5 \mathrm{~h}$. The reaction mixture was then evaporated to dryness, diluted with $\mathrm{DCM}(6 \mathrm{~mL})$ and 
339

340

341

342

343

344

345

346

347

348

349

350

351

352

353

354

355

356

357

358

359

360

361

362

363

364

365

366

367

368

369

370

371

372

373

374

375

376

377

378

extracted with saturated $\mathrm{NaHCO}_{3}$. The DCM layer was collected and washed several times with $\mathrm{d}-\mathrm{H}_{2} \mathrm{O}$ until $\mathrm{pH}$ of the solution was 7 . The combined DCM layer was dried over anhydrous $\mathrm{Na}_{2} \mathrm{SO}_{4}$ and evaporated to dryness. Prior to analysis of the prepared FAMEs by GC-FID analysis (6890N GC, California, USA), the formation of FAMEs was confirmed by ${ }^{1} \mathrm{H}-\mathrm{NMR}$ analysis (JNM-ECZ500R, Tokyo, Japan), where the singlet signal of the methoxy group at $\delta_{H} 3.65 \mathrm{ppm}$ was observed (Supplement 3).

\section{GC-FID analysis}

The prepared FAMEs of the fraction with the highest PPLI activity from the SiG60CC (250-mL size) fractionation was submitted to the Food Research and Laboratory (Faculty of Science, Chulalongkorn University) for analysis of its fatty acid components by GC-FID following the AOAC method 996.06. Briefly, chromatographic analysis was performed using a GC-FID system (Aglilent $6890 \mathrm{~N}$ ) equipped with an autosampler and split-splitless injector. A SPTM 2560 FULED SILICA capillary column with an internal diameter of $0.25 \mathrm{~mm}$ and $0.2 \mu \mathrm{m}$ film thickness was used for the chromatographic separation. Helium was used as the carrier gas at $1.1 \mathrm{~mL} / \mathrm{min}$. The injector and detector temperatures were set at 260 and $250{ }^{\circ} \mathrm{C}$, respectively. The initial GC oven temperature was $140{ }^{\circ} \mathrm{C}$, held for $5 \mathrm{~min}$, increased to $240{ }^{\circ} \mathrm{C}$ at $20^{\circ} \mathrm{C} / \mathrm{min}$, and held at $250{ }^{\circ} \mathrm{C}$ for 0.5 min. A volume of $1.0 \mu \mathrm{L}$ of sample was injected using the split injection mode (100:1).

The peaks were identified by comparison of their relative retention times with a standard FAME mixture. The results were expressed as $\mathrm{mg} / \mathrm{g}$ fatty acid.

\section{Data analysis}

Experiments were performed in triplicate. Numerical data are reported as the mean \pm one standard deviation ( \pm SD), determined in the Microsoft Excel 2019 software. Oneway ANOVA and T-test were used to test for significant differences in $\mathrm{IC}_{50}$ values. Tukey's test $(p<0.05)$ was applied for the pairwise multiple comparisons. The statistical analyses were performed using IBM SPSS statistics version 22 for windows.

The overall procedure of BP screening and enrichment for the PPLI active component in the most active extract is summarized schematically in Figure 1.

\section{Results}

\section{Palynological analysis of the six BP samples}

The major floral pollen types present in BP must be identified in order to report the type of floral pollen present in the BP. The simplest way is by morphology using LM and SEM analyses. Under LM and SEM, the morphology of bee pollen was observed. The pollen grains in BP1 were convex triangular with tricolporate, and the exine ornamentation was verrucate (Figures $2 \mathrm{~A}$ and $3 \mathrm{~A}$ ). This is consistent with the pollen grains of C. sinensis (L.) Kuntze (Ariyarathna et al., 2011; Fan et al., 2019). The pollen grains of BP2 were close to spherical with triaperturate, and the exine ornamentation 
379 was echinate (Figures $2 \mathrm{~B}$ and $3 \mathrm{~B}$ ), supported it to be the pollen grains of $H$. annuus $\mathrm{L}$.

380 (Ali et al., 2021). The pollen grains of BP3 were spherical or prolate spheroidal in shape

381

382

383

384

385

386

387

388

389

390

391

392

393

394

395

396

397

398

399

400

401

402

403

404

405

406

407

408

409

410

411

412

413

414

415

416 with four (tetrad) pollen subunits, and the exine ornamentation was tuberculate (Figures $2 \mathrm{C}$ and $3 \mathrm{C}$ ), supporting it to be the pollen grains of M. diplotricha (Lima et al., 2008; Peukpiboon et al., 2017). The pollen grains of BP4 were spherical in shape with tricolpate, and the exine ornamentation was uniformly dense reticulate (Figures 2D and 3D), supporting that they were the pollen grains of $N$. nucifera (Sangsuk et al., 2021; Zhang et al., 2019). The pollen grains of BP5 were ellipsoidal in polar view, flattened/convex in equatorial view with monosulcate and operculate, and the exine ornamentation was reticulate (Figures $2 \mathrm{E}$ and $3 \mathrm{E}$ ), they consitent with the pollen grains of $X$. complanata (da Luz et al., 2015). Finally, the pollen grains of BP6 were spherical in shape with tricolporate, and the exine ornamentation was echinate (Figures $2 \mathrm{~F}$ and $3 \mathrm{~F}$ ) confirming they were the pollen grains of $A$. conyzoides (Zafar et al., 2017; Garg, 1996).

\section{Identification of the pollen species in each BP sample by molecular analysis}

The six BP samples (BP1-6) were also identified by sequence analysis of the ITS-2 region of the rRNA genes. In each case, PCR amplification of the ITS-2 region gave an amplicon of the expected size (500 bp). After sequencing the amplicons and using them as the query sequence to BLASTn search the GenBank reference sequences, the same plant pollen species identifications were obtained as by the LM and SEM morphological analyses. Sample BP1 showed $100 \%$ nucleotide identity to the sequence of $C$. sinensis L. (accession \# MN242039.1), BP2 at 95.33\% nucleotide identity to the sequence of $H$. annuus L. (accession \# KF767534.1), BP3-6 at 100\% nucleotide identity to the sequence of $M$. diplotricha (accession \# MH768249.1), N. nucifera (accession \# FJ599761.1), X. complanata (accession \# MW113223), and A. conyzoides (accession \# KY700213.1), respectively.

Thus, the six BPs were confirmed to be essentially monofloral, matching the principal flowers around the hives, and with the morphological and molecular analyses congruent with each other. Thus, floral origin of each BP was clarified in this work.

\section{The partitioned extracts of BP}

For the six BPs, they were separately sequentially partitioned by $\mathrm{MeOH}, \mathrm{DCM}$, and hexane, three organic solvents with different polarities. The yield and character of all 18 obtained extracts (three solvents for each of BP1-6) are summarized in Table 1. The highest yield was obtained from the $\mathrm{MeOH}$-partitioned extracts in all six samples (above $40 \%$ ). Only a sticky solid form was obtained for the DCM-partitioned extracts, while an oil form was obtained in both the $\mathrm{MeOH}$ - and hexane-partitioned extracts. 
417

418

419

420

421

422

423

424

425

426

427

428

429

430

431

432

433

434

435

436

437

438

439

440

441

442

443

444

445

446

447

448

449

450

451

452

453

454

455

456

However, only the $\mathrm{MeOH}$ and DCM partitioned extracts of all six types of BP were tested for the three enzyme inhibitory activities because the hexane-partitioned extracts were insoluble in each of the respective enzyme assay buffer solutions.

\section{In vitro $\alpha$-amylase inhibitory activity}

The partitioned extracts were initially used at a final concentration of $2 \mathrm{mg} / \mathrm{mL}$, and the $\alpha$-amylase inhibitory activity (\%) is presented as the mean \pm SD in Table 2 . At this concentration, DCMXBP provided the highest in vitro a-amylase inhibitory activity (54.8 $\pm 2.8 \%$ ). The subsequent dose response assay revealed the anti $\alpha$-amylase activity of DCMXBP was concentration dependent (Figure 4A, supplement 1 ) with an $I_{50}$ value of $1,792.5 \pm 51.0 \mu \mathrm{g} / \mathrm{mL}$ (Table 2 ), which was markedly less effective than that of acarbose, the positive control (Figure 5A, supplement 2) with a 63-fold lower $\mathrm{IC}_{50}$ value of $28.1 \pm 2.7 \mu \mathrm{g} / \mathrm{mL}$. In contrast, DCMMBP and MTXBP had no real anti-a-amylase activity at this concentration of $2 \mathrm{mg} / \mathrm{mL}(1.19 \pm 2.06 \%$ and $0.00 \pm 0.00 \%$, respectively).

\section{In vitro AChEl activity}

The partitioned extracts were initially screened for AChEl activity at a final concentration of $500 \mu \mathrm{g} / \mathrm{mL}$. The in vitro AChEl activity (\%) is presented as the mean \pm SD in Table 2. At this concentration, DCMCBP provided the highest AChEl activity at $19.3 \pm 1.5 \%$. However, the AChEl activity of all the partitioned extracts were negligible compared to that of physostigmine, the positive control, with an over 230 -fold lower $\mathrm{IC}_{50}$ value of $0.082 \pm 0.002 \mu \mathrm{g} / \mathrm{mL}$ (Figure 5B and Table 2, supplement 2).

\section{In vitro PPLI activity}

The partitioned extracts were initially screened for PPLI activity at a final concentration of $400 \mu \mathrm{g} / \mathrm{mL}$ with the results (as the \% PPLI activity) presented as the mean \pm SD in Table 2. This concentration was selected because it was the highest concentration that could be totally dissolved in DMSO. At this concentration, some DCM partitioned extracts showed a PPLI activity close to $50 \%$, and so they were further evaluated at different concentrations. The PPLI activity was found to be dosedependent (Figure 4B, supplement 1) and broadly similar between DCMCBP and DCMMBP, with $\mathrm{IC}_{50}$ values of $458.5 \pm 13.4$ and $500.8 \pm 24.8 \mu \mathrm{g} / \mathrm{mL}$, respectively. However, they were markedly less effective than orlistat, the positive control, with an over 21,800-fold lower $\mathrm{IC}_{50}$ value of $0.021 \pm 0.000 \mu \mathrm{g} / \mathrm{mL}$ (Figure $5 \mathrm{C}$, supplement 2).

\section{In vitro PPLI activity of active compounds from DCMMBP}

Fractionation of DCMMBP by SiG60-CC

From Table 2, although the DCMCBP and DCMMBP had no marked difference in their PPLI activity $\left(\mathrm{IC}_{50}\right.$ of $458.5 \pm 13.4$ and $500.8 \pm 24.8 \mu \mathrm{g} / \mathrm{mL}$, respectively), DCMMBP was selected for further fractionation by SiG60-CC because there have been 
457 numerous previous studies on the lipase inhibitory activity of Camellia sinensis $L$ (Chen 458 et al., 2020), but the lipase inhibitory activity of $M$. diplotricha flower BP has not been 459 reported yet.

$460 \quad$ From $5.64 \mathrm{~g}$ of DCMMBP, a total of 74 fractions were collected. After comparison of 461

462

463

464

465

466

467

468

469

470

471

472

473

474

475

476

477

478

479

480

481

482

483

484

485

486

487

488

489

490

491

492

493

494

495

496 their TLC profiles and pooling fractions with a similar pattern, five different fractions (DCMMBP1-5) were obtained. Their weight, yield, and appearance are summarized in Table 3. All five pooled fractions were a sticky solid. Fraction DCMMBP5 provided the highest yield $(42.20 \%)$. These five pooled fractions were then tested for their PPLI activity, with the results shown in Figure $4 \mathrm{C}$ and the derived $\mathrm{IC}_{50}$ values reported in Table 3 (supplement 1). Fraction DCMMBP2 gave the highest PPLI activity $\left(\mathrm{IC}_{50}\right.$ of $128.5 \pm 3.0 \mu \mathrm{g} / \mathrm{mL})$.

Since the DCMMBP2 fraction had the highest PPLI activity, it was further enriched by SiG60-CC (250-mL size) to yield a total of 150 fractions. After a pooling of fractions with similar TLC profiles, three different fractions (DCMMBP2-1, DCMMBP2-2, and DCMMBP2-3) were obtained. Their weight, yield, and appearance are summarized in Table 3. With respect to their PPLI activity (Figure 4C), fraction DCMMBP2-1 had the highest PPLI activity $\left(\mathrm{IC}_{50}\right.$ of $52.6 \pm 3.5 \mu \mathrm{g} / \mathrm{mL}$ ), while DCMMBP2-2 and DCMMBP2-3 had essentially no PPLI activity.

\section{Principal chemical composition analysis (TLC and NMR) of fractions DCMMBP2-1 and DCMMBP2-2}

After SiG60-CC, the chemical composition of the three obtained fractions was tested by TLC (Figure 6). For DCMMBP2-1, no band was observed under UV light at $254 \mathrm{~nm}$ (Figure 6A), but a dark blue spot was found after dipping in 3\% (v/v) anisaldehyde in $\mathrm{MeOH}$ and heating over a hot plate (Figure 6B). The structure of fraction DCMMBP 2-1 was first analyzed by ${ }^{1} \mathrm{H}-\mathrm{NMR}$, where the signal at $\delta 0.85$ to $2.85 \mathrm{ppm}$ and the signal at $\delta 5.35 \mathrm{ppm}$ showed the characteristics of unsaturated free fatty acids (UFFAs; Supplement 4). Therefore, fraction DCMMBP2-1 was prepared as FAMEs for the GCFID analysis.

In contrast, only a sharp band was observed on the TLC plate for fraction DCMMBP2-2, which indicated it was enriched to apparent homogeneity (potentially pure) compound. Therefore, the chemical structure of the compound, named compound 1 , in fraction DCMMBP2-2 was analyzed by ${ }^{1} \mathrm{H}-\mathrm{NMR}$. Compared to naringenin isolated from the M. pigra L. flower BP (Khongkarat et al., 2021), the obtained NMR peaks in the chemical shift pattern were ${ }^{1} \mathrm{H}-\mathrm{NMR}(500 \mathrm{MHz}, \mathrm{MeOH}-\mathrm{d} 4) \delta: 7.30(\mathrm{~d}, \mathrm{~J}=8.5 \mathrm{~Hz}, 2 \mathrm{H})$, $6.80(\mathrm{~d}, 8.5 \mathrm{~Hz}, 2 \mathrm{H}), 5.86$ (q, J=2.2 Hz, 2H), 5.33 (dd, J=13.0, 3.0 Hz, 1H), 3.09 (dd, $\mathrm{J}=17.1,13.0 \mathrm{~Hz}, 1 \mathrm{H}$ ), and $2.67(\mathrm{dd}, \mathrm{J}=17.1,3.0 \mathrm{~Hz}, 1 \mathrm{H}$ ) (Supplement 5). Thus compound 1 was identified as naringenin (Figure 7A). However, the structure of DCMMBP2-3 was not identified from the NMR results because it did not have any marked PPLI activity. 
497

498 Analysis of the fatty acids of fraction DCMMBP2-1The fatty acids were identified 499 and divided into saturated fatty acids (SFAs) without $\mathrm{C}=\mathrm{C}$ double bonds,

500 monounsaturated fatty acids (MUFAs) with one such bond, and polyunsaturated fatty 501 acids (PUFAs) with two or more double bonds between two connected carbon atoms.

502 The fatty acid content in DCMMBP2-1 is summarized in Table 4. The major fatty acids 503 included one SFA (palmitic acid) and two PUFAS (linoleic and linolenic) (Figure 7B-7D), 504 together with small amounts of stearic acid, oleic acid, myristic acid, pentadecanoic 505 acid, lignoceric acid, margaric acid, ecosadienoic acid, eicosenoic acids, $\gamma$-linolenic 506 acid, behenic acid, palmitoleic acid, heptadecenoic acid, and eicosanoic acid 507 (Supplement 6). 
508

509

510

511

512

513

514

515

516

517

518

519

520

521

522

523

524

525

526

527

528

529

530

531

532

533

534

535

536

537

538

539

540

541

\section{Discussion}

Aging societies are found in most developed and many developing countries due to the leap in progress in medicine and standard of living (nutrition, shelter, etc.) leading to people living longer. However, these new life styles, especially in the increased access to goods and processed food exposes the population to face many diseases, such as diabetics, Alzeimer's, and obesity. The drugs to treat these diseases are expensive, especially when imported, as is the case in Thailand. These include acarbose and orlistat as expensive anti-diabetic as anti-obesity drugs, respectively. In addition, those drugs can cause adverse side effects. Orlistat can cause several mild-to-moderate gastrointestinal adverse effects, serious adverse hepatic effects, and rare cases of acute kidney injury. In addition, it interferes with the absorption of many drugs, resulting in their decreased bioavailability and effectiveness (Filippatos et al., 2008).

Hence, finding alternative treatments from local, sustainable, and natural products is necessary. Many types of fruit, vegetables, and mushrooms (fungi) have been shown to inhibit a-amylase activity (Papoutsis et al., 2021), while a mixture of flavonoids and phenolics acids from Aristotelia chilensis leaves and coumarins have potential AChEI activity (Cespedes et al., 2017; de Souza et al., 2016). In addition, lipase inhibitors have been reported from both synthetic compounds (phosphonates, boronic acids, fats analogues) and natural compounds from many spices and plants, such as hydroxybenzoic acids, hydroxycinnamic acid, flavonol, isoflavonoid, flavanone, and hydroxycoumarin from Momordica charantia fruits (Bialecka-Florjanczyk et al., 2018; Chanda et al., 2019; Sellami et al., 2017).

In this work, BP harvested by $A$. mellifera, the most well managed honeybee, was our target. Due to the rapid growth of industries in Thailand, many agricultural areas have become fragmented and the agroecosystem has been changed into monocrop cultures, which results in a higher proportion of bee hives having monofloral BP. As known, the bioactivity of BP is mainly dependent on its botanical origin (Rebiai and Lanez, 2012). Thus, the monofloral BP from various botanical and geographical origins in Thailand was the focus of this study. With the standard methods used in pollen identification (Bell et al., 2016), the six BP samples in this work were ascribed to have originated from $C$. sinensis $L$., $H$. annuus $L$., M. diplotricha, N. nucifera, $X$. complanata, and $A$. conyzoides for BP1-6, respectively. Three bioactivities (anti-amylase, AChEl, and PPLI activities) were focused on because there have been rare reports on these activities in BP, especially in Thailand. 
$542 \quad$ Although in vitro assays were used, the obtained data was reliable. The anti-

543 amylase activity was performed using $\alpha$-amylase from porcine pancreas, which shows a

544 close relationship to human a-amylase (Butterworth et al., 2011). For the AChEl activity,

545 AChE from electric eel, which has the same active site as human AChE, was selected

546 (Orhan et al., 2011), while PPL has a similar active site to human pancreatic lipase was

547 used in the anti-lipase assay (Winkler et al., 1990). Therefore, these in vitro assays

548 were used as a screening method to search for potential human enzyme inhibitors.

549 Bioactivity could be found in either the crude/partition extracts, partially purified

550 extracts or pure form (Feas et al., 2012; Khongkarat et al., 2020). In the crude partition

551 extracts of this study, only DCMXBP showed anti-amylase activity. With respect to the

552 AChEl activity, only one of the partition extracts showed a weak AChEl activity. For the

553 anti-lipase (as PPLI) activity, all the DCM partition extracts showed PPLI activity, but

554 with only a weak PPLI activity shown by DCMHBP. In contrast, DCMMBP and

555 DCMCBP showed a moderate PPLI activity. Thus, DCM is the best partition solvent for

556 our extraction method. However, these three activities were reported previously in the

557 methanolic extracts of mono- and hetero-floral BP in Brazil (Araújo et al., 2017) and the

558 anti-amylase activity was found in the aqueous-ethanolic extract of BP in Nigeria

559 (Daudu et al., 2019). Thus, the solvent and extraction method used could not be

560 ignored.

$561 \quad$ Among the three bioactivities examined in this study, the PPLI activity of $M$.

562 diplotricha BP became the main interest in this study due to the scarcity of reports on 563 this activity in BP. Thus, DCMMBP from M. diplotricha BP was further fractionated by 564 SG60 CC two times. After enrichment, two interesting fractions were derived and the 565 chemical structure of the components in these two fractions was analyzed by ${ }^{1} \mathrm{H}-\mathrm{NMR}$.

566 One was found to be a mixture of FFAs and showed the highest PPLI activity, while the 567 other fraction was naringenin, a flavanone compound that has been reported in Mimosa 568 pigra L. bee pollen (Khongkarat et al., 2021). Therefore, it can be used as a marker of 569 Mimosa spp. bee pollen. 
570

571

572

573

574

575

576

577

578

579

580

581

582

583

584

585

586

587

588

589

590

591

592

593

594

595

596

597

598

599

600

601

602

603

604

605

606

607

608

609

610

To study the FFA composition, the fatty acid fraction was esterified to FAME and analyzed by GC-FID following the AOAC method 996.06. The result showed that this fraction consisted of two major PUFAs (linoleic acid at $49.75 \%$ and $\alpha$-linolenic at $18.43 \%$ ) and one major SFA (palmitic acid at $24.77 \%$ ). The major fatty acid composition of $M$. diplotricha BP is consistent with the fatty acid compositions that have been reported previously (Araújo et al., 2017), except that linoleic acid was found at the highest proportion in our study and not a-linolenic acid. It is possible that linoleic acid provided the observed PPLI activity in M. diplotricha BP, consistent with the previously reported anti-lipase activity of a fatty acid mixture from Nigella sativa extracts with linoleic acid as the dominant fatty acid. This showed a mixed inhibition type (the inhibitor can bind to enzyme whether or not the enzyme has already bound the substrate) (Shamsiya et al., 2016). The lipase enzyme active site at Ser152 is within a hydrophobic hexapeptide sequence (Val-Gly-His-Ser-Gln-Gly) (Duan, 2000), and the long $\mathrm{HC}$ chain of linoleic acid can bind with lipase via hydrophobic interactions.

Overall, the results indicate that $M$. diplotricha BP has an anti-lipase property due to its FFA composition, which is safe to consume and has the potential to be developed for use as a pharmaceutical supplement.

\section{Conclusions}

Active biomolecule analysis of BP with PPLI activity contributed to a deeper characterisation of BP. The highest PPLI activity was revealed in A. mellifera monofloral MP dominant in $M$. diplotricha floral pollen. Floral identification ensured both the safety for consumption and the standard of quality control. Although naringenin was found not to have a PPLI activity in this work and was also without any antioxidant activity in a previous study, it could be used as a marker for monofloral BP dominant in Mimosa spp. The FFAs found in this bee product are here reported to present an in vitro lipase inhibitory activity. Thus, this work promotes the use of bee products as a natural nutrient supplement and indicates the benefit of Mimosa spp., which are generally regarded as only weeds. However, in vivo assessment is still required.

\section{List of abbreviations}

BP1: bee pollen of Camellia sinensis L., BP2: bee pollen of Helianthus annuus L., BP3: bee pollen of Mimosa diplotricha, BP4: bee pollen of Nelumbo nucifera, BP5: bee pollen of Xyris complanata, and BP6: bee pollen of Ageratum conyzoides

DCMCBP: DCM partitioned extract of $C$. sinensis L. bee pollen, DCMBP: DCM partitioned extract of $H$. annuus L. bee pollen, DCMMBP: DCM partitioned extract of $M$. diplotricha bee pollen, DCMNBP: DCM partitioned extract of $N$. nucifera bee pollen, DCMXBP: DCM partitioned extract of $X$. complanata bee pollen, DCMABP: DCM partitioned extract of $A$. conyzoides bee pollen

HXCBP: hexane partitioned extract of $C$. sinensis L. bee pollen, HXHBP: hexane partitioned extract of $H$. annuus $L$. bee pollen, HXMBP: hexane partitioned extract of $M$. 
611 diplotricha bee pollen, HXNBP: hexane partitioned extract of $N$. nucifera bee pollen, 612 HXXBP: hexane partitioned extract of $X$. complanata bee pollen, HXABP: hexane 613 partitioned extract of $A$. conyzoides bee pollen

614 MTCBP: $\mathrm{MeOH}$ partitioned extract of $C$. sinensis L. bee pollen, MTHBP: $\mathrm{MeOH}$

615

616

617

618

619

620

621

622

623

624

625

626

627

628

629

630

631

632

633

634

635

636

637

638

639

640

641

642

643

644

645

646

647

648

649

650

651

652

653

654

655

656 partitioned extract of $H$. annuus $L$. bee pollen, MTMBP: MeOH partitioned extract of $M$. diplotricha bee pollen, MTNBP: MeOH partitioned extract of $N$. nucifera bee pollen, MTXBP: $\mathrm{MeOH}$ partitioned extract of $X$. complanata bee pollen, MTABP: $\mathrm{MeOH}$ partitioned extract of $A$. conyzoides bee pollen

DCMMBP1-5: pooled fraction 1-5 after SiG60-CC (500-mL size) of DCMMBP

DCMMBP2-1, 2-2, and 2-3: pooled fraction 1, 2, and 3 after SiG60-CC (250-mL size) of DCMMBP2

\section{References}

Akoro SM, Ogundare CO, Oladipupo OR. 2017. Phytochemical study and alphaamylase inhibitory properties of leaf extracts of Croton zambesicus (Müll. Arg.). Biotechnology Journal International 18:1-8 DOI: 10.9734/BJI/2017/32441.

Ali N, Akhtar N, Khan SA, UI Uza N. 2021. Palynological investigation of selected species of family Asteraceae using light and scanning electron microscopic techniques. Microscopy Research and Technique 84:261-270 DOI: 10.1002/jemt. 23583.

Arathi HS, Bjostad L, Bernklau E. 2018. Metabolomic analysis of pollen from honey bee hives and from canola flowers. Metabolomics 14:86 DOI: 10.1007/s11306-0181381-5.

Araujo JS, Chambo ED, de Carvalho Costa MAP, da Silva SMPC, de Carvalho CAL, Estevinho LM. 2017. Chemical composition and biological activities of mono- and heterofloral bee pollen of different geographical origins. International Journal of Molecular Sciences 18:921 DOI: 10.3390/ijms18050921.

Ariyarathna HACK, Gunasekare MTK, Kottawa-Arachchige JD, Paskarathevan R, Ranaweera KK, Ratnayake M, Kumara JBDAP. 2011. Morpho-physiological and phenological attributes of reproductive biology of tea (Camellia sinensis (L.) O. Kuntze) in Sri Lanka. Euphytica 181:203-215 DOI: 10.1007/s10681-011-0399-9.

Bell KL, de Vere N, Keller A, Richardson RT, Gous A, Burgess KS, Brosi BJ. 2016. Pollen DNA barcoding: current applications and future prospects. Genome 59:629640 DOI: 10.1139/gen-2015-0200.

Bialecka-Florjanczyk E, Fabiszewska AU, Krzyczkowska J, Kurylowicz A. 2018. Synthetic and natural lipase inhibitors. Mini-Reviews in Medicinal Chemistry 18:672683 DOI: 10.2174/1389557516666160630123356.

Butterworth PJ, Warren FJ, Ellis PR. 2011. Human a-amylase and starch digestion: an interesting marriage. Starch-Stärke 63:395-405 DOI: doi.org/10.1002/star.201000150.

Cespedes CL, Balbontin C, Avila JG, Dominguez M, Alarcon J, Paz C, Burgos V, Ortiz L, Penaloza-Castro I, Seigler DS, Kubo I. 2017. Inhibition on cholinesterase and tyrosinase by alkaloids and phenolics from Aristotelia chilensis leaves. Food and Chemical Toxicology 109(Pt 2):984-995 DOI: 10.1016/j.fct.2017.05.009.

Chanda J, Mukherjee PK, Biswas R, Malakar D, Pillai M. 2019. Study of pancreatic lipase inhibition kinetics and LC-QTOF-MS-based identification of bioactive 
657

658

659

660

661

662

663

664

665

666

667

668

669

670

671

672

673

674

675

676

677

678

679

680

681

682

683

684

685

686

687

688

689

690

691

692

693

694

695

696

697

698

699

700

constituents of Momordica charantia fruits. Biomedical Chromatography 33:e4463 DOI: $10.1002 /$ bmc.4463.

Chantarudee A, Phuwapraisirisan P, Kimura K, Okuyama M, Mori H, Kimura A, Chanchao C. 2012. Chemical constituents and free radical scavenging activity of corn pollen collected from Apis mellifera hives compared to floral corn pollen at Nan, Thailand. BMC Complementary and Alternative Medicine 12:45 DOI: 10.1186/14726882-12-45.

Chen D, Chen G, Sun Y, Zeng X, Ye H. 2020. Physiological genetics, chemical composition, health benefits and toxicology of tea (Camellia sinensis L.) flower: a review. Food Research International 137:109584 DOI: 10.1016/j.foodres.2020.109584.

Costa MCA, Morgano MA, Ferreira MMC, Milani RF. 2019. Quantification of mineral composition of Brazilian bee pollen by near infrared spectroscopy and PLS regression. Food Chemistry 273:85-90 DOI: 10.1016/j.foodchem.2018.02.017.

Da Luz CFP, dos Santos VL, Guedes JS, de Oliveira Silva-Cobra G, Wanderley MGL. 2015. Pollen morphology of some Brazilian Xyris Gronov. ex L. (Xyridaceae) species. Brazilian Journal of Botany 38:937-950 DOI: 10.1007/s40415-015-0192-4.

Daudu OM. 2019. Bee pollen extracts as potential antioxidants and inhibitors of $\alpha-$ amylase and $\alpha$-glucosidase enzymes in vitro assessment. Journal of Apicultural Science 63:315-325 DOI: 10.2478/jas-2019-0020.

De Souza LG, Renna MN, Figueroa-Villar JD. 2016. Coumarins as cholinesterase inhibitors: a review. Chemico-Biological Interactions 254:11-23 DOI: 10.1016/j.cbi.2016.05.001.

Di Pasquale G, Salignon M, Le Conte Y, Belzunces LP, Decourtye A, Kretzschmar A, Suchail S, Brunet JL, Alaux C. 2013. Influence of pollen nutrition on honey bee health: do pollen quality and diversity matter? PLoS One 8:e72016 DOI: 10.1371/journal.pone.0072016.

Duan RD. 2000. Fat Digestion and Absorption. AOCS Press, Champaign III Coden 69ACBA Conference.

Fan TF, Potroz MG, Tan EL, Ibrahim MS, Miyako E, Cho NJ. 2019. Species-specific biodegradation of sporopollenin-based microcapsules. Scientific Reports 9:1-13 DOI: 10.1038/s41598-019-46131-w.

Fatrcova-Sramkova K, Nozkova J, Kacaniova M, Mariassyova M, Rovna K, Stricik M. 2013. Antioxidant and antimicrobial properties of monofloral bee pollen. Journal of Environmental Science and Health, Part B 48:133-138 DOI: 10.1080/03601234.2013.727664.

Feas X, Vazquez-Tato MP, Estevinho L, Seijas JA, Iglesias A. 2012. Organic bee pollen: botanical origin, nutritional value, bioactive compounds, antioxidant activity and microbiological quality. Molecules 17:8359-8377 DOI: 10.3390/molecules17078359.

Filippatos TD, Derdemezis CS, Gazi IF, Nakou ES, Mikhailidis DP, Elisaf MS. 2008. Orlistat-associated adverse effects and drug interactions: a critical review. Drug Safety 31:53-65 DOI: 10.2165/00002018-200831010-00005.

Garg A. 1996. Palynocontents of bee-collected pollen loads of autumn season in Bhimal, India. Taiwania 41:197-207 DOI: 10.6165/tai.1996.41.197. 
701

702

703

704

705

706

707

708

709

710

711

712

713

714

715

716

717

718

719

720

721

722

723

724

725

726

727

728

729

730

731

732

733

734

735

736

737

738

739

740

741

742

743

744

745
Ghoshal KP, Saoji AA. 2013. Phytochemical screening of the pollen of some selected plants with antidiabetic properties. Australian Journal of Basic and Applied Sciences 7:105-109

Jagdis A, Sussman G. 2012. Anaphylaxis from bee pollen supplement. Canadian Medical Association Journal 184:1167-1169 DOI: 10.1503/cmaj.112181.

Jamous RM, Abu-Zaitoun SY, Akkawi RJ, Ali-Shtayeh MS. 2018. Antiobesity and antioxidant potentials of selected palestinian medicinal plants. Evidence-Based Complementary and Alternative Medicine 2018:1-21 DOI: 10.1155/2018/8426752.

Khongkarat P, Ramadhan R, Phuwapraisirisan P, Chanchao C. 2020. Safflospermidines from the bee pollen of Helianthus annuus L. exhibit a higher in vitro antityrosinase activity than kojic acid. Heliyon 6:e03638 DOI: 10.1016/j.heliyon.2020.e03638.

Khongkarat P, Ramadhan R, Phuwapraisirisan P, Chanchao C. 2021. Screening and bioguided fractionation of Mimosa pigra $\mathrm{L}$. bee pollen with antioxidant and antityrosinase activities. Journal of Apicultural Science 65:71-83 DOI:10.2478/jas-20210001.

Kostic AZ, Milincic DD, Nedic N, Gasic UM, Trifunovic BS, Vojt D, Tesic ZL, Pesic MB. 2021. Phytochemical profile and antioxidant properties of bee-collected artichoke (Cynara scolymus) pollen. Antioxidants 10:1091 DOI: 10.3390/antiox10071091.

Li F, Guo S, Zhang S, Peng S, Cao W, Ho CT, Bai N. 2019. Bioactive constituents of $F$. esculentum bee pollen and quantitative analysis of samples collected from seven areas by HPLC. Molecules 24:1-15 DOI: 10.3390/molecules24152705.

Lima LCL, Silva FHM, Santos FDARD. 2008. Palinologia de espécies de Mimosa L. (Leguminosae-Mimosoideae) do semi-árido brasileiro. Acta Botanica Brasilica 22:794-805 DOI: 10.1590/S0102-33062008000300016.

Lopes AJO, Vasconcelos CC, Garcia JBS, Doria Pinheiro MS, Pereira FAN, Camelo DS, de Morais SV, Freitas JRB, da Rocha CQ, de Sousa Ribeiro MN, do Socorro de Sousa Cartágenes M. 2020. Anti-inflammatory and antioxidant activity of pollen extract collected by Scaptotrigona affinis postica: in silico, in vitro, and in vivo studies. Antioxidants 9:103 DOI: 10.3390/antiox9020103.

Lopes AJO, Vasconcelos CC, Pereira FAN, Silva RHM, Queiroz PFDS, Fernandes CV, Garcia JBS, Ramos RM, Rocha CQD, Lima STJRM, Cartágenes MDSS, Ribeiro MNS. 2019. Anti-inflammatory and antinociceptive activity of pollen extract collected by stingless bee Melipona fasciculata. International Journal of Molecular Sciences 20:4512 DOI: 10.3390/ijms20184512.

Maqsood M, Ahmed D, Atique I, Malik W. 2017. Lipase inhibitory activity of Lagenaria siceraria fruit as a strategy to treat obesity. Asian Pacific Journal of Tropical Medicine 10:305-310 DOI: 10.1016/j.apjtm.2017.03.010.

Munoz E, Velasquez P, Rodriguez K, Montenegro G, Giordano A. 2020. Influence of Brassica campestris and Galega officinalis on antioxidant activity of bee pollen. Revista Brasileira de Farmacognosia 30:444-449 DOI: 10.1007/s43450-020-00065$\mathrm{x}$.

Orhan IE, Khan MTH, Erdem SA, Kartal M, Sener B. 2011. Selective cholinesterase inhibitors from Buxus sempervirens L. and their molecular docking studies. Current Computer-Aided Drug Design 7:276-286 DOI: 10.2174/157340911798260296. 
746 Papoutsis K, Zhang J, Bowyer MC, Brunton N, Gibney ER, Lyng J. 2021. Fruit,

747

748

749

750

751

752

753

754

755

756

757

758

759

760

761

762

763

764

765

766

767

768

769

770

771

772

773

774

775

776

777

778

779

780

781

782

783

784

785

786

787

788

789

790 vegetables and mushrooms for the preparation of extracts with a-amylase and $\alpha$ glucosidase inhibition properties: a review. Food Chemistry 338:128119 DOI: 10.1016/j.foodchem.2020.128119.

Peukpiboon T, Benbow ME, Suwannapong G. 2017. Detection of Nosema spp. spore contamination in commercial Apis mellifera bee pollens of Thailand. Journal of Apicultural Research 56:376-386 DOI: 10.1080/00218839.2017.1327936.

Rattanawannee A, Chanchao C. 2011. Bee Diversity in Thailand and the Applications of Bee Products, In: Changing Diversity in Changing Environment, O Grillo, G Venora, (Ed.), 133-162, InTech, Vienna, Austria.

Rebiai A, Lanez T. 2012. Chemical composition and antioxidant activity of Apis mellifera bee pollen from northwest Algeria. Journal of Fundamental and Applied Sciences 4:155-163 DOI: 10.4314/jfas.v4i2.5.

Richardson RT, Lin CH, Sponsler DB, Quijia JO, Goodell K, Johnson RM. 2015. Application of ITS2 metabarcoding to determine the provenance of pollen collected by honey bees in an agroecosystem. Applications in Plant Sciences 3:1-6 DOI: 10.3732/ apps.1400066.

Rzepecka-Stojko A, Stojko J, Kurek-Gorecka A, Gorecki M, Kabała-Dzik A, Kubina R, Mozdzierz A, Buszman E. 2015. Polyphenols from bee pollen: structure, absorption, metabolism and biological activity. Molecules 20:21732-21749. DOI: 10.3390/molecules201219800.

Sangsuk R, Baslev H, Jampeetong A. 2021. Pollen morphology in various life-form of aquatic macrophytes. Chiang Mai University Journal of Natural Sciences 20:1-11 DOI: 10.12982/CMUJNS.2021.050.

Sellami M, Louati H, Kamoun J, Kchaou A, Damak M, Gargouri Y. 2017. Inhibition of pancreatic lipase and amylase by extracts of different spices and plants. International Journal of Food Sciences and Nutrition 68:313-320 DOI: 10.1080/09637486.2016.1237479.

Shahali Y. 2015. Allergy after ingestion of bee-gathered pollen: influence of botanical origins. Annals of Allergy, Asthma and Immunology 114:250-251 DOI: 10.1016/j.anai.2014.11.009.

Shamsiya TK, Manjunatha JR, Manonmani HK. 2016. Lipase inhibitors from Nigella sativa and Punica granatum as an effective approach towards controlling obesity. International Journal of Health and Life Sciences 2:1-9 DOI: 10.20319/lijhls.2016.22.0119.

Vieths S, Scheurer S, Ballmer-Weber B. 2002. Current understanding of cross-reactivity of food allergens and pollen. Annals of the New York Academy of Sciences 964:47$68 \mathrm{https}: / /$ doi.org/10.1111/j.1749-6632.2002.tb04132.x.

Winkler FK, d'Arcy A, Hunziker W. 1990. Structure of human pancreatic lipase. Nature 343:771-774 DOI: 10.1038/343771a0.

Yang K, Wu D, Ye X, Liu D, Chen J, Sun P. 2013. Characterization of chemical composition of bee pollen in China. Journal of Agricultural and Food Chemistry 61:708-718 DOI: 10.1021/jf304056b.

Zafar M, Ahmad M, Khan MA. 2007. Palynology of family Asteraceae from flora of Rawalpindi-Pakistan. International Journal of Agriculture and Biology 9:156-161 
791 Zhang D, Chen Q, Liu Q, Liu F, Cui L, Shao W, Tian D. 2019. Histological and cytological characterization of anther and appendage development in Asian lotus (Nelumbo nucifera Gaertn.). International Journal of Molecular Sciences 20:1-15 DOI: 10.3390/ijms20051015.

Zou Y, Hu J, Huang W, Zhu L, Shao M, Dordoe C, Ahn YJ, Wang D, Zhao Y, Xiong Y, Wang X. 2020. The botanical origin and antioxidant, anti-BACE1 and antiproliferative properties of bee pollen from different regions of South Korea. BMC

800 Complementary Medicine and Therapies 20:236 DOI: 10.1186/s12906-020-030231. 


\section{Table 1 (on next page)}

The weight, yield, and character of the partitioned extracts. 
Table 1

\begin{tabular}{llll} 
Sample & Weight $(\mathrm{g})$ & Yield $(\%)$ & Character \\
\hline MTCBP & 64.93 & 46.38 & Pale brown oil \\
DCMCBP & 7.41 & 5.29 & Sticky dark brown solid \\
HXCBP & 7.73 & 5.52 & Dark brown oil \\
MTHBP & 79.97 & 57.12 & Dark brown oil \\
DCMHBP & 12.55 & 8.96 & Sticky dark brown solid \\
HXHBP & 8.98 & 6.41 & Dark brown oil \\
MTMBP & 57.90 & 41.36 & Dark brown oil \\
DCMMBP & 9.89 & 7.06 & Sticky dark brown solid \\
HXMBP & 7.43 & 5.31 & Dark brown oil \\
MTNBP & 79.49 & 56.8 & Pale brown oil \\
DCMNBP & 4.68 & 3.34 & Sticky brown solid \\
HXNBP & 5.31 & 3.79 & Pale brown oil \\
MTXBP & 96.81 & 69.15 & Dark brown oil \\
DCMXBP & 8.04 & 56.8 & Sticky dark brown solid \\
HXXBP & 11.7 & 8.36 & Dark brown oil \\
MTABP & 79.28 & 56.63 & Dark brown oil \\
DCMABP & 5.75 & 4.11 & Sticky dark brown solid \\
HXABP & 8.47 & 6.05 & Dark brown oil \\
\hline
\end{tabular}

2 


\section{Table 2 (on next page)}

The percentage of enzyme inhibition (mean \pm S.D.) and $I C_{50}$ value $(\mu \mathrm{g} / \mathrm{mL}$ ) of the partitioned extracts. 
1 Table 2

\begin{tabular}{|c|c|c|c|}
\hline Sample & $\alpha$-amylase / IC 50 & $\mathrm{AChE} / \mathrm{IC}_{50}$ & PPLI / IC 50 \\
\hline MTCBP & $16.12 \pm 1.81 /-$ & $7.74 \pm 0.23 /-$ & $7.74 \pm 0.56 /-$ \\
\hline DCMCBP & $38.58 \pm 3.87 /-$ & $19.25 \pm 1.50 /-$ & $49.47 \pm 1.31 / 458.48 \pm 13.38^{b}$ \\
\hline MTHBP & $14.31 \pm 0.99 /-$ & $11.34 \pm 0.92 /-$ & $29.86 \pm 1.15 /-$ \\
\hline DCMHBP & $42.70 \pm 2.49 /-$ & $8.23 \pm 1.97 /-$ & $3.65 \pm 1.72 /-$ \\
\hline MTMBP & $11.68 \pm 1.05 /-$ & $13.95 \pm 1.51 /-$ & $14.38 \pm 1.38 /-$ \\
\hline DCMMBP & $1.19 \pm 2.06 /-$ & $10.22 \pm 3.72 /-$ & $42.89 \pm 2.23 / 500.80 \pm 24.76^{b}$ \\
\hline MTNBP & $7.92 \pm 1.12 /-$ & $4.13 \pm 0.47 /-$ & $31.58 \pm 0.64 /-$ \\
\hline DCMNBP & $4.50 \pm 2.88 /-$ & $5.91 \pm 1.74 /-$ & $39.49 \pm 1.48 / 876.09 \pm 24.15^{\mathrm{c}}$ \\
\hline MTXBP & $0.00 \pm 0.00 /-$ & $7.37 \pm 1.71 /-$ & $38.51 \pm 0.13 /-$ \\
\hline DCMXBP & $54.82 \pm 2.76 / 1,792.48 \pm 50.96^{b}$ & $7.76 \pm 3.67 /-$ & $35.09 \pm 1.04 / 960.49 \pm 38.19^{\mathrm{e}}$ \\
\hline MTABP & $13.72 \pm 1.44 /-$ & $6.81 \pm 0.85 /-$ & $14.53 \pm 0.94 /-$ \\
\hline DCMABP & $41.45 \pm 4.23 /-$ & $9.95 \pm 3.59 /-$ & $37.38 \pm 2.39 / 646.09 \pm 19.41^{\circ}$ \\
\hline Acarbose & $-/ 28.08 \pm 2.65^{a}$ & - & - \\
\hline Physostigmine & & $-/ 0.082 \pm 0.002$ & - \\
\hline Orlistat & - & - & $-/ 0.021 \pm 0.000^{a}$ \\
\hline
\end{tabular}

2 Remark: The $\mathrm{IC}_{50}$ values were calculated using nonlinear regression except for

3 DCMNBP and orlistat that were calculated using linear regression. Data are shown as

4 the mean. Within a column, means with a different superscript letter are significantly

5 different $[p<0.05$; One-way ANOVA for anti-amylase activity $(p=0.000)$ and Post Hoc

6 (Tukey) test for anti-lipase activity ( $p=0.000$ except $p$ between DCMNBP and DCMXBP

$7=0.008]$. 


\section{Table 3 (on next page)}

Characteristics and PLLI activity (IC 50 value) of all pooled fractions after the first (500-mL column) and second (250-mL colume) SiG60-CC fractionation. 
1 Table 3

\begin{tabular}{|c|c|c|c|c|}
\hline Sample & $\begin{array}{l}\text { Weight } \\
\text { (mg) }\end{array}$ & $\begin{array}{l}\text { Yield } \\
(\%)\end{array}$ & Appearance & $\mathrm{IC}_{50}(\mu \mathrm{g} / \mathrm{mL})$ \\
\hline \multicolumn{5}{|c|}{ After $1^{\text {st }}$ SiG60-CC: } \\
\hline DCMMBP1 & 210 & 3.72 & Sticky brown solid & - \\
\hline DCMMBP2 & 300 & 5.32 & Sticky brown solid & $128.48 \pm 3.01^{\mathrm{c}}$ \\
\hline DCMMBP3 & 2,060 & 36.52 & Sticky pale-yellow solid & - \\
\hline DCMMBP4 & 410 & 7.27 & Sticky brown solid & - \\
\hline DCMMBP5 & 2,380 & 42.20 & Sticky dark brown solid & - \\
\hline Orlistat & - & - & & $0.021 \pm 0.00^{a}$ \\
\hline \multicolumn{5}{|c|}{ After $2^{\text {nd }}$ SiG60-CC: } \\
\hline DCMMBP2-1 & 65.7 & 21.9 & Sticky brown solid & $52.63 \pm 3.50^{b}$ \\
\hline DCMMBP2-2 & 38.5 & 12.83 & Yellow solid & - \\
\hline DCMMBP2-3 & 60.5 & 20.17 & Brown solid & - \\
\hline Orlistat & - & - & & $0.021 \pm 0.00^{a}$ \\
\hline
\end{tabular}

2 Remark: The $\mathrm{IC}_{50}$ values of orlistat and DCMXBP2 were calculated from a linear

3 regression, while that for DCMMBP2-1 was calculated from non-linear regression.

4 Values are shown as the mean. Means with a different superscript letter are significantly

5 different $(p=0.000$ between DCMMBP2 and orlistat and $p=0.001$ between

6 DCMMBP2-1 and orlistat; Independent-Samples T-Test). DCMMBP2-2 was initially

7 called compound $\mathbf{1}$ and later identified as naringenin. 
Table 4 (on next page)

Fatty acid composition of the DCMMBP2-1 (as FAMEs). 
1 Table 4

\begin{tabular}{clllcc}
\hline $\begin{array}{c}\text { Peak } \\
\#\end{array}$ & \multicolumn{1}{c}{ Fatty acid } & \multicolumn{1}{c}{ Type } & Abbreviation & $\begin{array}{c}\text { Retention time } \\
(\mathrm{min})\end{array}$ & $\begin{array}{c}\text { Fatty acid } \\
(\mathrm{mg} / \mathrm{g})\end{array}$ \\
\hline 1 & Myristic acid & SFAs & C14: 0 & 20.187 & 4.4292 \\
2 & Pentadecanoic acid & SFAs & C15: 0 & 21.877 & 3.1227 \\
3 & Palmitic acid & SFAs & C16: 0 & 23.586 & 247.7186 \\
4 & Palmitoleic acid & MUFAs & C16: 1 & 24.766 & 1.6687 \\
5 & Margaric acid & SFAs & C17: 0 & 25.196 & 2.9375 \\
6 & Heptadecenoic acid & MUFAs & C17: 1 & 26.224 & 1.3405 \\
7 & Stearic acid & SFAs & C18: 0 & 26.773 & 18.9883 \\
8 & Oleic acid & MUFAs & C18: $1 \mathrm{n} 9 \mathrm{c}$ & 27.768 & 16.5952 \\
9 & Linoleic acid & PUFAs & C18: $2 \mathrm{n} 6 \mathrm{c}$ & 29.316 & 497.5391 \\
10 & Eicosanoic acid & SFAs & C20: 0 & 29.799 & 1.0764 \\
11 & F-linolenic acid & PUFAs & C18: 3n6 & 30.379 & 2.2933 \\
12 & Eicosenoic acids & MUFAs & C20: 1 & 30.717 & 2.5925 \\
13 & a-linolenic acid & PUFAs & C18: $3 n 3$ & 30.930 & 184.2923 \\
14 & Ecosadienoic acid & PUFAs & C20: 2 & 32.155 & 2.6826 \\
15 & Behenic acid & SFAs & C22: 0 & 32.663 & 1.8952 \\
16 & Lignoceric acid & SFAs & C24: 0 & 35.655 & 3.0019 \\
\hline
\end{tabular}

2

3 
Figure 1

Summary for extraction, screening and enrichment procedures for the selected BP. 


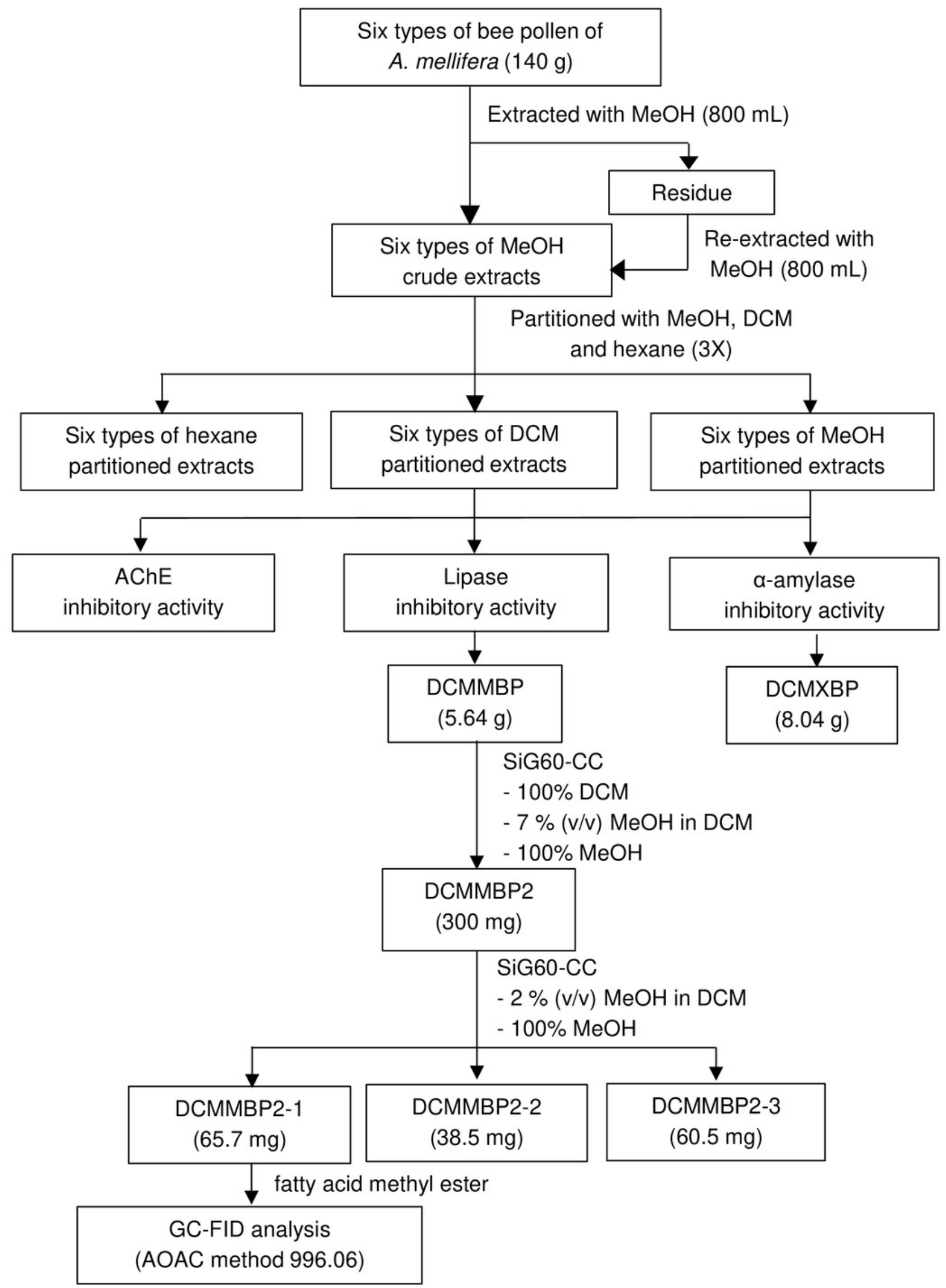




\section{Figure 2}

Representative LM images of (A-F) BP1-6, respectively, identified as (A) C. sinensis L., (B) H. annuus L., (C) M. diplotricha, (D) N. nucifera, (E) X. complanata, and (F) A. conyzoides flower pollen.

(A)

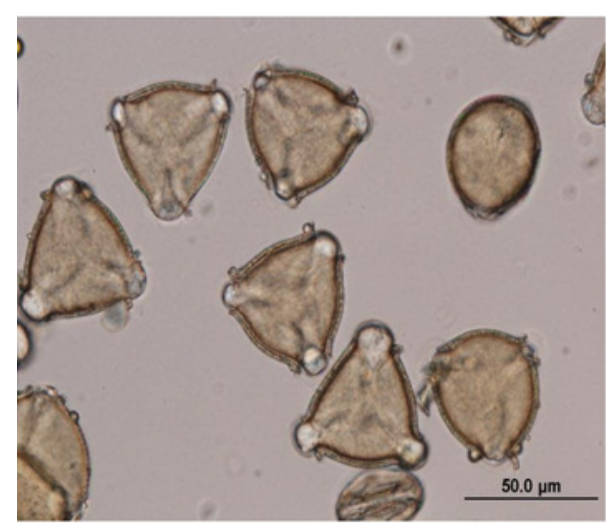

(D)

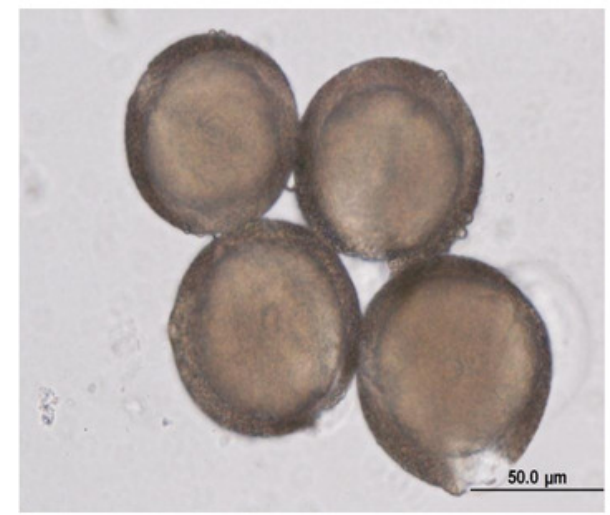

(B)

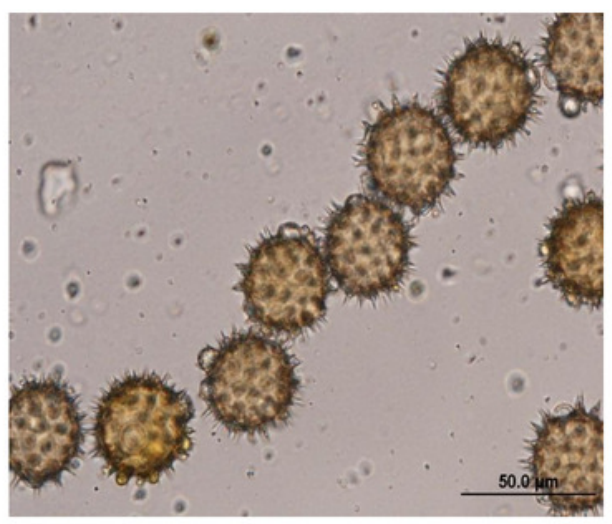

(E)

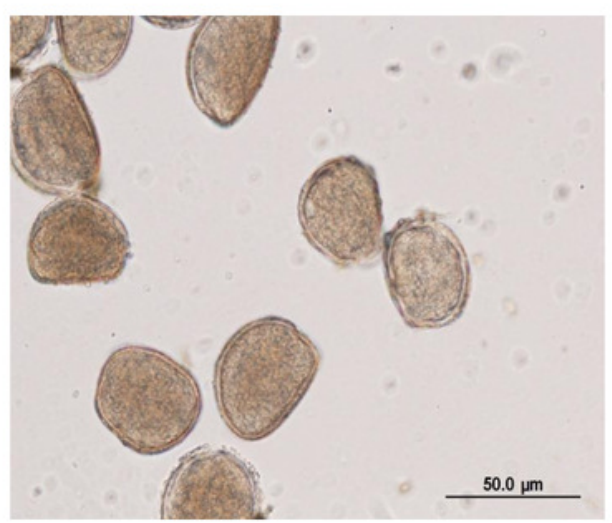

(C)

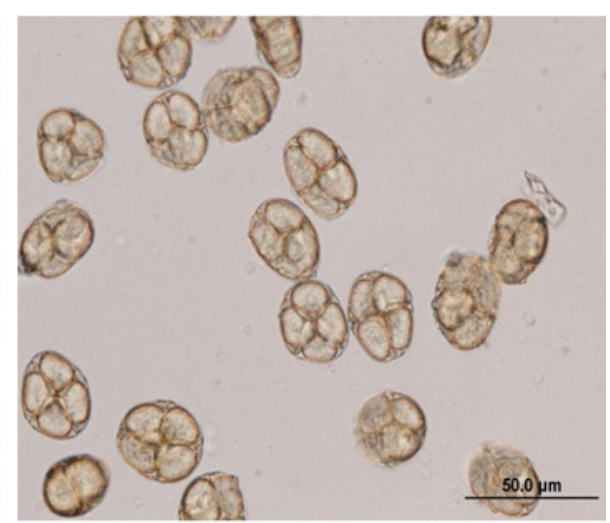

(F)

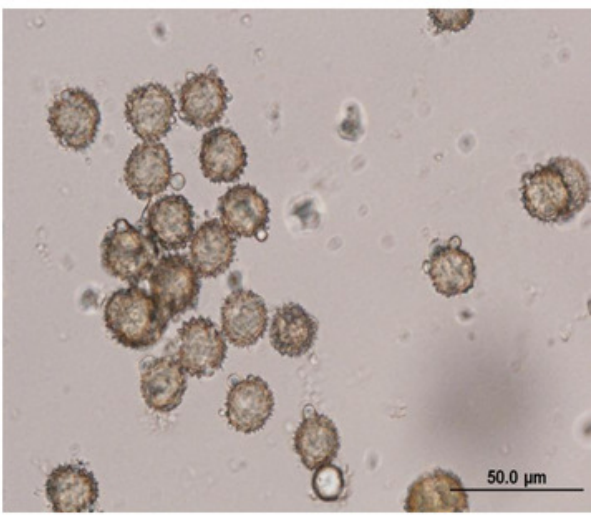




\section{Figure 3}

Representative SEM images of (A-F) BP1-6, respectively, identified as (A) C. sinensis $L$., (B) H. annuus L., (C) M. diplotricha, (D) N. nucifera, (E) X. complanata, and (F) A. conyzoides flower pollen.

(A)

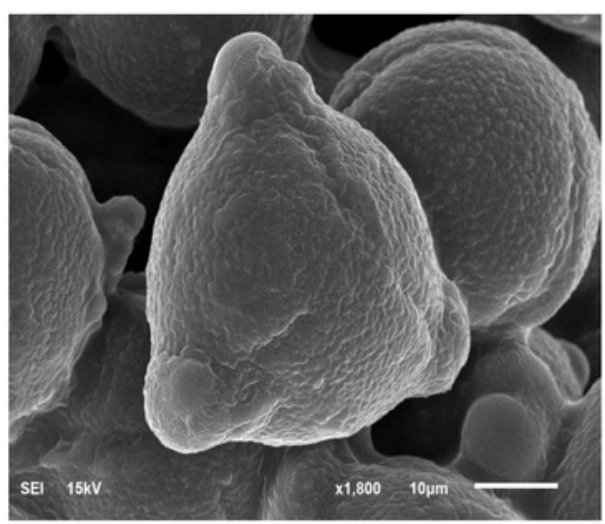

(D)

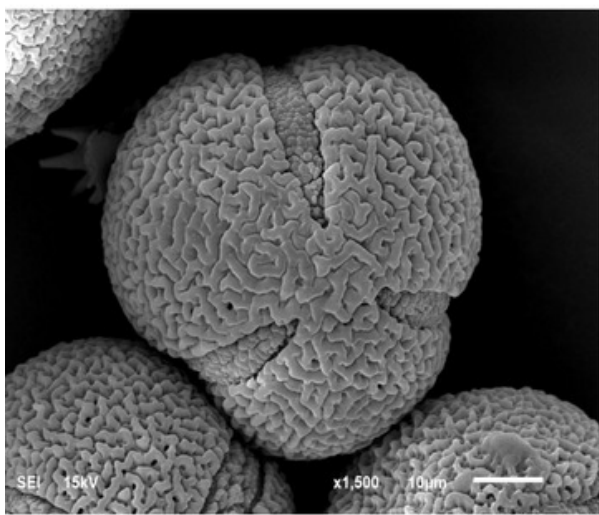

(B)

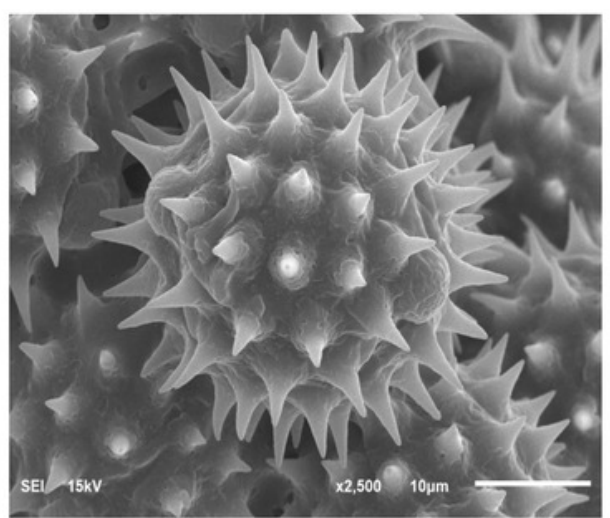

(E)

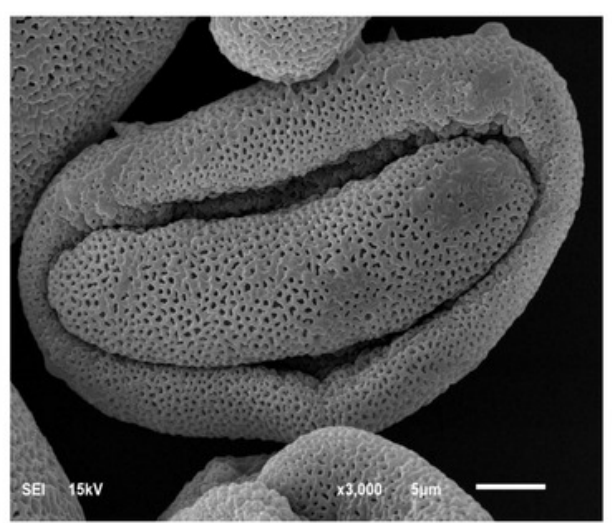

(C)

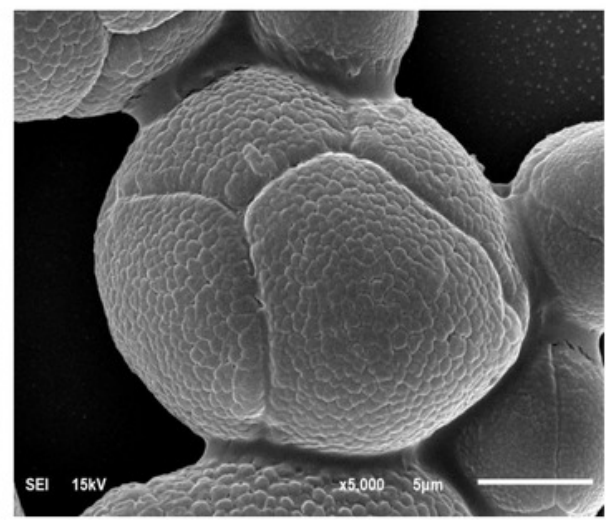

(F)

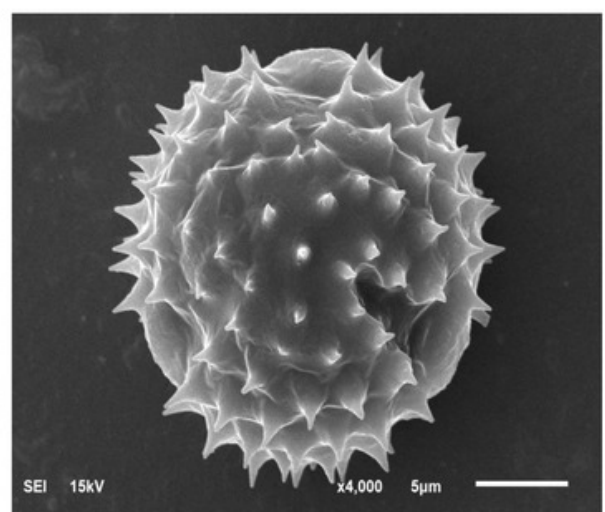


Figure 4

The (A) $\alpha$-amylase inhibition activity (\%) of DCMXBP, (B) PPLI activity (\%) of DCM partitioned extracts, and (C) PPLI activity (\%) of DCMMBP2 and DCMMBP2-1. Data are shown as the mean \pm SD.

(A)

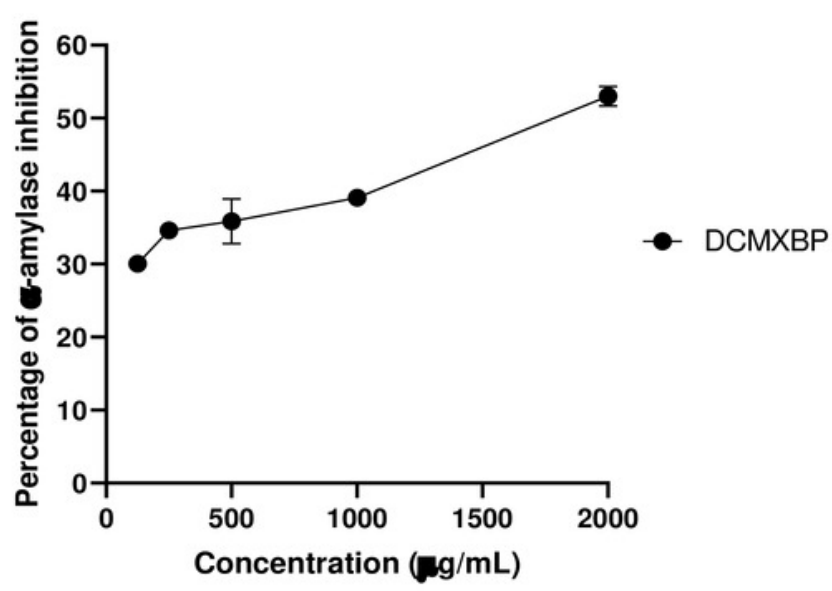

(B)

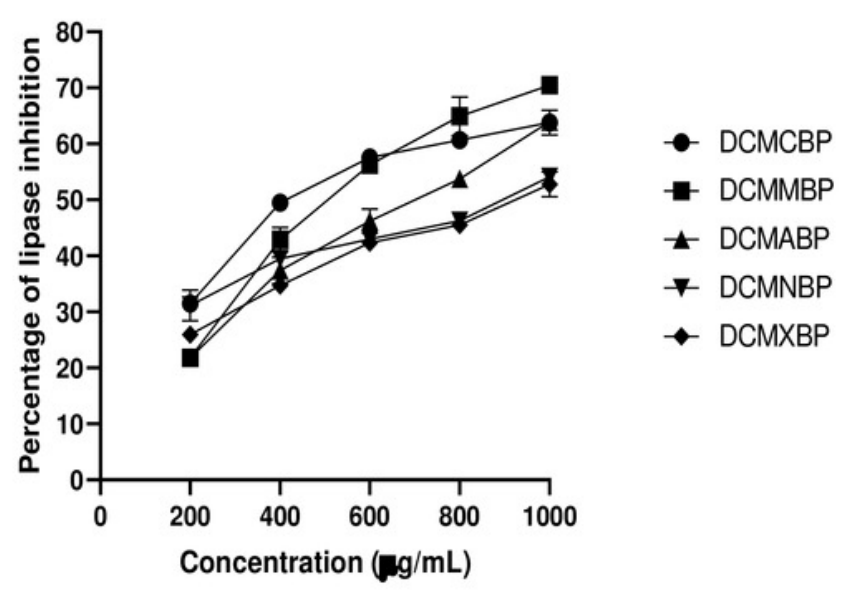

(C)

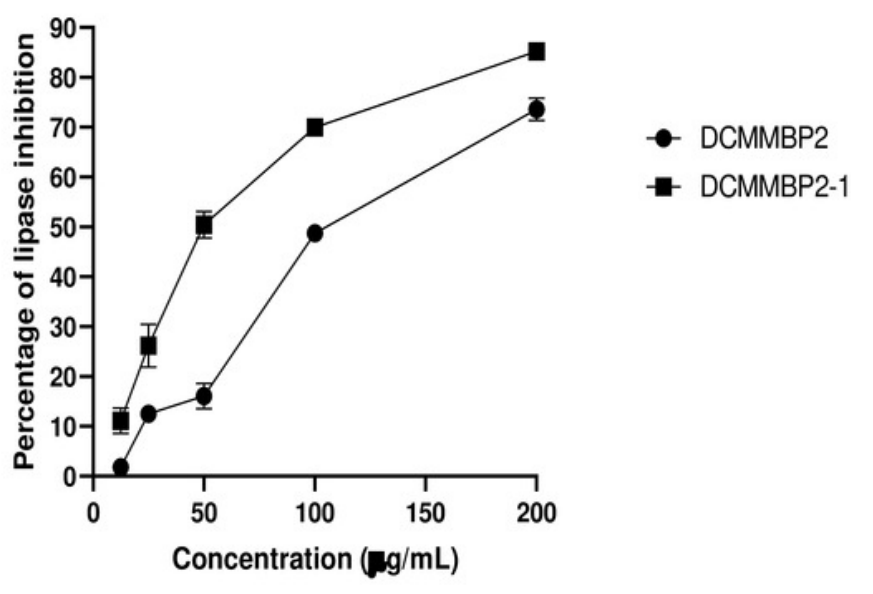


Figure 5

The (A) $\alpha$-amylase inhibition (\%) of acarbose, (B) AChEl activity (\%) of physostigmine, and (C) PPLI activity (\%) of orlistat. Data are shown as the mean \pm SD.

(A)

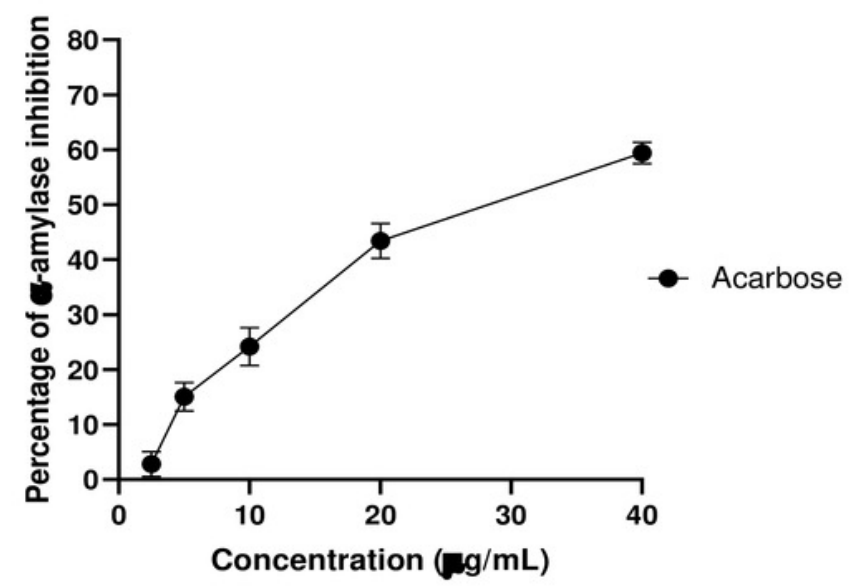

(B)

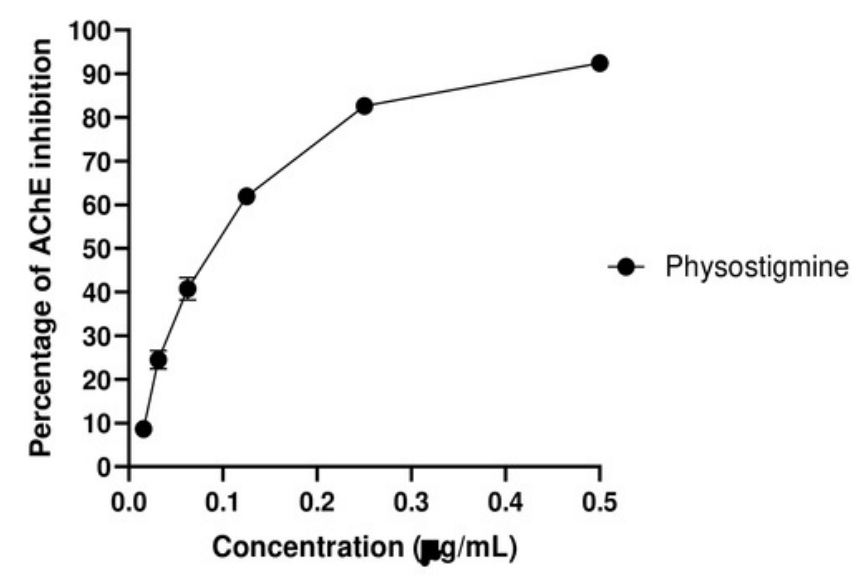

(C)

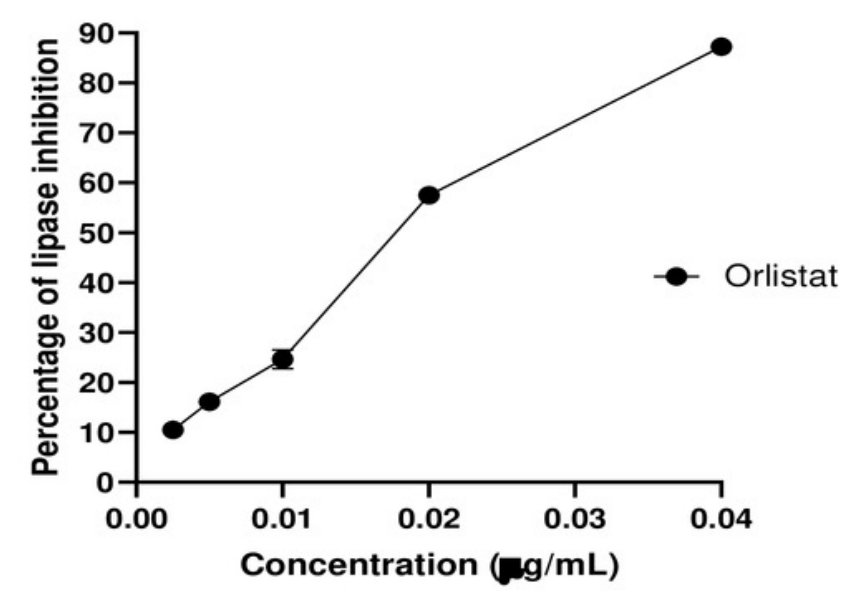




\section{Figure 6}

TLC images showing the profile of DCMMBP2 (lane 1), DCMMBP2-1 (lane 2), DCMMBP2-2 (lane 3), DCMMBP2-3 (lane 4), and naringenin (lane 5) under (A) UV light and (B) after $3 \%(\mathrm{v} / \mathrm{v})$ anisaldehyde in $\mathrm{MeOH}$.

\section{(A)}

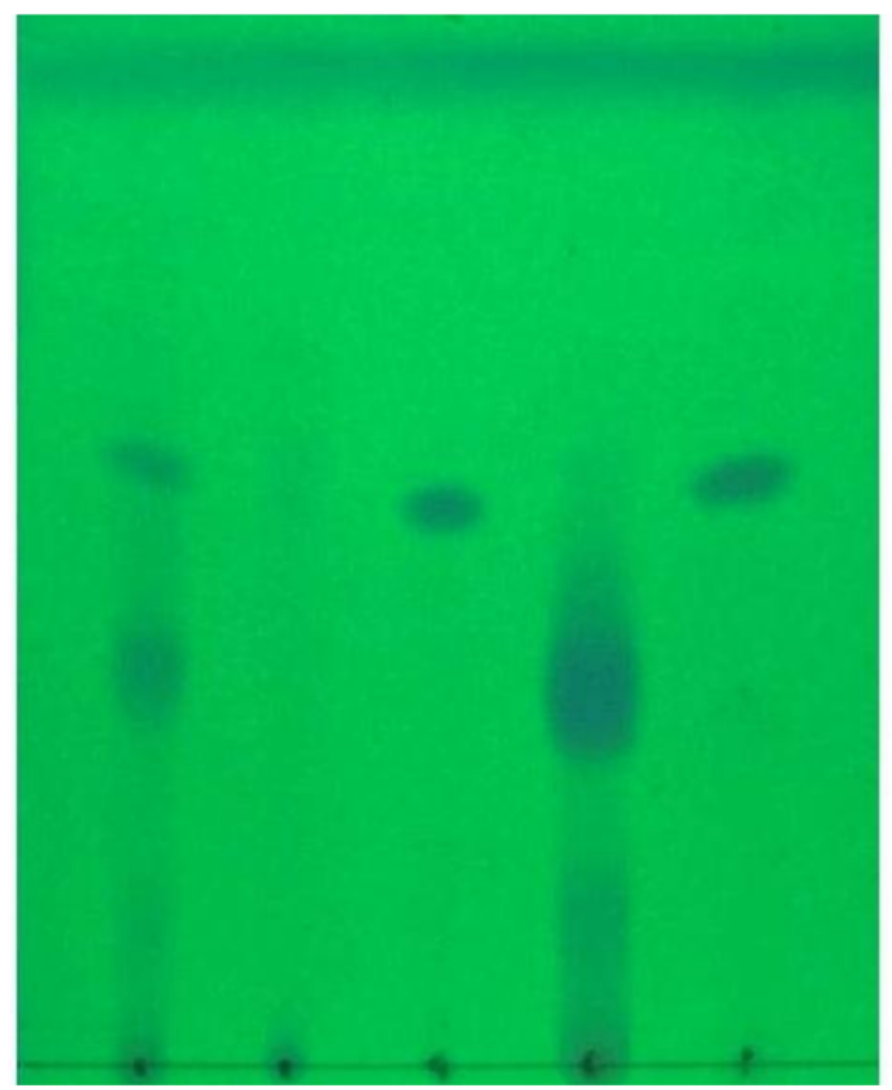

(B)

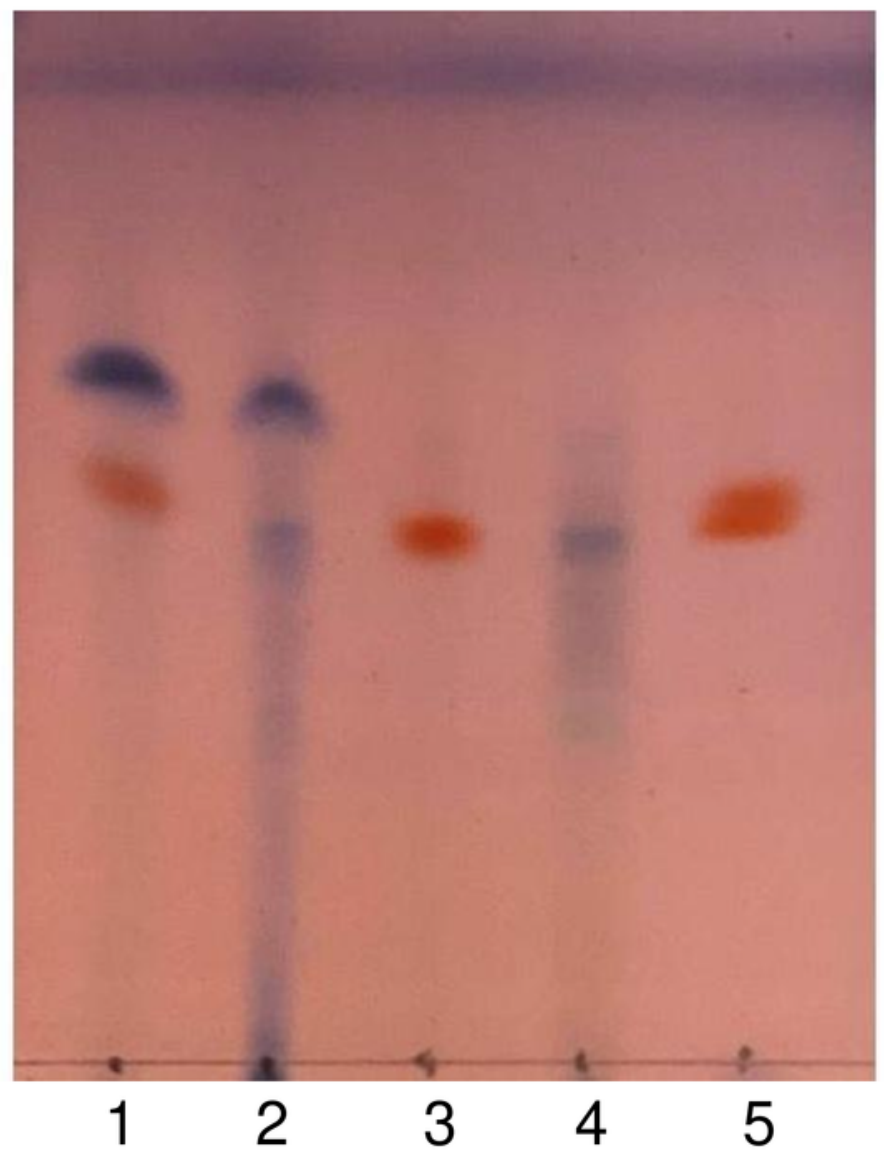


Figure 7

Structural formula of naringenin (A) and the chemical structures of palmitic acid, C16:0 (B), linoleic acid, C18:2n6c (C), and $\alpha$-linolenic acid, C18:3n3 (D).

(A)

(B)<smiles>O=C1CC(c2ccc(O)cc2)Oc2cc(O)cc(O)c21</smiles><smiles>CCCCCCCCCCCCCCCC(O)=C(C)O</smiles>

(C)<smiles>CCCCC/C=C\C/C=C\CCCCCCCC(=O)O</smiles>

(D)

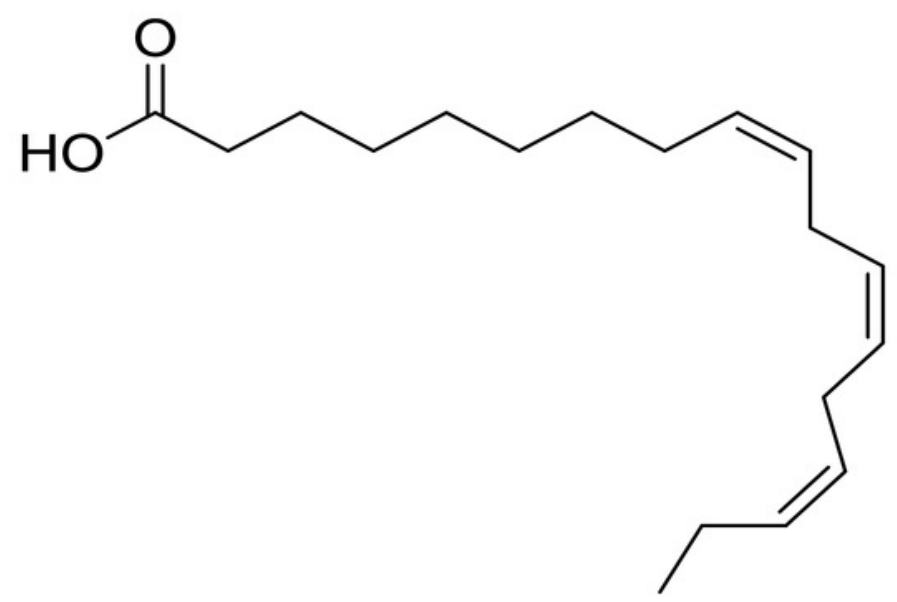

